\title{
Francisco Heylan. Revisión biográfica del calcógrafo e impresor flamenco asentado en Andalucía ${ }^{1}$
}

\author{
Ana María PÉrez GaldeAno \\ Universidad de Granada \\ Departamento de Historia del Arte \\ ampg@ugr.es
}

Recibido: $25-02-2014$

Aceptado: 09-10-2014

\section{RESUMEN}

Trabajo que revisa la biografía del calcógrafo e impresor Francisco Heylan (1584-1635). Ofrece datos inéditos basados en nuevas fuentes documentales que han generado mayor exactitud y precisión acerca de los acontecimientos referidos a su historia y su quehacer profesional. Se resalta de modo especial la aproximación del año de fallecimiento de Francisco Heylan, quien fue el principal miembro de una saga de notables burilistas de origen flamenco afincados en Andalucía. Se pone de manifiesto el estatus social sustentado por esta familia, tanto en su origen, como en su establecimiento en Granada. Destacando de modo sobresaliente su labor en el arte de la imprenta y el éxito de su taller.

Palabras clave: Francisco Heylan; Bernardo Heylan; Justino Antolínez de Burgos; grabado; aguafuerte y buril; Abadía del Sacro Monte; Sevilla; Granada; Andalucía; Amberes; s. 17.

\section{Francisco Heylan. Biographical review of the flemish engraver and printer, settled in Andalusia}

\begin{abstract}
This work revises the biography of Francisco Heylan engraver and printer (1584-1635). It offers new documentary sources that have generated greater accuracy and precision about the events related to his history and his professional work. We highlight in a special way the discovery of the year of death of Francisco Heylan, who was the principal member of a remarkable family of engravers of Flemish origin settled in Andalusia. We have revealed his family social status, both in its origin and in its establishment
\end{abstract}

1 El estudio que aquí se presenta conforma un capítulo relevante de la tesis doctoral defendida el 23 de enero de 2014 en la Universidad de Granada titulada Los descubrimientos del Sacro Monte y los inicios del grabado calcográfico en Andalucía: nuevas aportaciones a los grabadores peninsulares y flamencos que lo hicieron posible, dirigida por el Catedrático Dr. Antonio Moreno Garrido, cuyos resultados han permitido ampliar los aspectos conocidos hasta el momento sobre los artífices, así como se presenta un catálogo razonado de toda su obra. 
in Granada. And we include new information over his dedication to the art of typography and the success of his workshop.

Key words: Francisco Heylan; Bernardo Heylan; Justino Antolínez de Burgos; engraving; etching and buril; Abbey of Sacro Monte; Seville; Granada; Andalusia; Antwerp; $17^{\text {th }}$ century.

\section{Preámbulo}

Después de un trabajo de campo en archivos y centros de documentación diversos se ha visto la necesidad de ofrecer una biografía actualizada y documentada del grabador e impresor Francisco Heylan, donde las fuentes documentales han marcado el discurso que aquí se propone. Así, se tratará de poner en relación los nuevos datos encontrados estableciendo un diálogo crítico con lo que hasta ahora se conocía de este grabador.

La historiografía ya se había ocupado de exponer algunas conclusiones acerca de los trabajos conocidos e inéditos de este importante grabador ${ }^{2}$. Sin embargo, en ellos se hacía evidente ciertas lagunas en lo relativo no sólo a su vida personal, sino también acerca de su otra ocupación como impresor de libros. Por tanto, no sólo era necesario exponer los nuevos datos biográficos encontrados del grabador, sino que además era preciso que éstos fueran puestos en relación con esa otra faceta desarrollada por Francisco en el arte de la imprenta para alcanzar un conocimiento más amplio de este artista flamenco.

El grabado calcográfico andaluz de la primera mitad del XVII, empleado fundamentalmente para la ilustración de libros, estuvo muy ligado a esta familia procedente de Amberes: Francisco y Bernardo Heylan. La venida de estos hermanos de origen flamenco, primero a Sevilla y después a Granada, hábiles en el manejo de la técnica del buril marcará la actividad calcográfica de estas dos importantes ciudades y del resto de Andalucía. Así sus estampas serán un referente iconográfico para otros artistas de la época, como grabadores y pintores, que encontrarán en sus grabados una fuente de inspiración seguida con gran interés.

2 MORENO GARRIDO, Antonio, «El Arte del Grabado en Granada durante el siglo XVII. I la calcografía». Cuadernos de Arte de la Universidad de Granada, 26-28 (1976), p. 57; MORENO GARRIDO, Antonio, «Contribución al estudio de la estampa sevillana en la primera mitad del siglo XVII: Francisco Heylan en Sevilla (1606-1611)». En: Tercer Congreso Español de Historia del Arte. Sevilla, 1980; MORENO GARRIDO, Antonio, «La etapa sevillana de Francisco Heylan». En: Cuadernos de Arte de la Universidad de Granada. XVI (1984), pp. 349-358; SÁNCHEZ MARTÍN, Carlos; CRUZ ALCAÑIZ, Cándido de la, «Un nuevo grabado de F. Heylan». Cuadernos de arte Universidad de Granada. 37(2006), pp. 385-389; PINILLA, $\mathrm{M}^{\mathrm{a}}$ José, «Melius est ergo duos esse simul: la iconografía singular de un grabado de Francisco Heylan». En: Estudios de Historia del Arte. Homenaje al profesor de la Plaza Santiago. Coord. Jesús Ma Parrado y Fernando Gutiérrez. Valladolid: Universidad de y Diputación de, 2009, pp. 377-381; MORENO GARRIDO, Antonio; PÉREZ GALDEANO, Ana $\mathrm{M}^{\mathrm{a}}$, «El frontispicio o portada, antecedente en imágenes del contenido del libro Barroco: El Teatro de las Religiones de fray Pedro de Valderrama, 1612». Cuadernos de Arte de la Universidad de Granada. 40 (2009), pp. 69-82. 
La historiografía ${ }^{3}$ justificó el establecimiento de los Heylan en el sur de la Península como una consecuencia directa del efecto llamada generado entre sus compatriotas ${ }^{4}$ por una ciudad tan activa y próspera como lo fue la Sevilla del último tercio del siglo XVI. Ciertamente esta ciudad estuvo llena de grandes oportunidades para comerciantes y artistas, ya que por entonces en ella se estableció el control de las rutas comerciales con el nuevo mundo por medio de la Casa de Contratación. Hecho que generó el absoluto control y monopolio de la ciudad con respecto al tránsito comercial hacia los nuevos territorios. Este vínculo tan directo con los nuevos enclaves dará lugar al establecimiento, en sus barrios y municipios, de numerosas casas conventuales de las principales órdenes religiosas presentes en la Península, deseosas éstas de fomentar su labor evangelizadora en las tierras americanas. Todo ello junto con la existencia de una rica nobleza de cuna, generó un ambiente propicio para los artistas que tuvieron que responder a la nueva demanda cultural, devocional y de representación con unos matices distintos a la demandada en la Corte de un marcado carácter áulico ${ }^{5}$. Es así que la ciudad hispalense, como Granada y el resto de Andalucía posteriormente, llegará a concentrar una gran cantidad de artistas; unos para satisfacer la demanda local; y otros en búsqueda de nuevas oportunidades en tierras americanas ${ }^{6}$.

El posterior traslado de Francisco y Bernardo Heylan a Granada y su definitivo asentamiento en esta ciudad vendrá motivado por dos hechos fundamentales. En primer lugar, Francisco llegará a la ciudad atraído por el importante encargo de ilustrar la Historia Eclesiástica de Granada a petición de Justino Antolínez, como se podrá ver a continuación. En segundo lugar, el definitivo asentamiento de Francisco Heylan en esta ciudad se debió a que éste intuyó el enorme vacío existente en ella de grabadores en hueco y la oferta de trabajo que eso supondría para su persona. Sobre todo teniendo en cuenta que en Granada se encontraba la Real Chancillería, y a ella vinculada personas distinguidas del ámbito jurídico, social, político y religioso que serán una importante fuente de encargos calcográficos. A partir de 1617 Francisco desarrollará una nueva faceta como impresor, ligada estrechamente a la presencia en la ciudad de esta importante institución judicial que junto a los encargos calcográficos, se convertirán en sus principales actividades hasta el final de su vida.

3 MORENO GARRIDO, op. cit., 1976, p. 57.

4 PÁEZ, Elena, Antología del grabado español, quinientos años de su arte en España: Catálogo-guía de la Exposición preparada por la Sección de Estampas bajo la dirección de Elena Páez. Madrid: Hauser y Menet, 1952, p. 12; LAFUENTE FERRARI, Enrique, «Una antología del grabado español. Sobre la historia del grabado en España». Clavileño, 18 (1952), pp. 39-40; AINAUD, Juan, «Grabado». En: Ars Hispaniae. Historia Universal del Arte Hispánico. Madrid: Editorial Plus Ultra, t. 18, 1962, pp. 275-276. NAVARRETE PRIETO, Benito: La pintura andaluza del siglo XVII y sus fuentes grabadas. Madrid: Fundación de Apoyo a la Historia del Arte Hispánico, 1998.

5 BLAS BENITO, Javier; CARLOS, M ${ }^{\text {a }}$ Cruz de; MATILLA, José Manuel: Grabadores extranjeros en la Corte española del Barroco. Madrid: Biblioteca Nacional; Centro de Estudios Europa Hispánica, 2011, p. 23.

6 NAVARRETE PRIETO, Op. cit., 1998, pp. 77-83. 


\section{Noticias sobre su entorno familiar en Amberes}

Hijo de Bernardo Heylan y Ana de Guillermo, ${ }^{7}$ Francisco Heylan nació en Amberes en torno a $1584^{8}$. Año que se deduce a partir de los testimonios de quienes declararon como testigos -entre ellos su propio hermano Bernardo-, en su unión matrimonial con doña Ana de Godoy ${ }^{9}$ con quien se casó en Granada el 29 de octubre de $1612^{10}$. Francisco pasó su juventud en Amberes junto a sus padres y su hermano quien además dice $«[\ldots]$ donde le a tratado de hordinario $\left[\right.$ sic] $[\ldots] » .{ }^{11}$ Sin que por el momento haya sido posible saber si éstos tuvieron algún otro hermano o hermana más. A la luz de los documentos hasta ahora conocidos y los nuevos aportados respecto a esta cuestión, llevan a pensar que la familia estuvo formada por Bernardo Heylan, doña Ana de Guillermo y sus dos únicos hijos varones, Francisco y Bernardo.

Lo único que hasta ahora se conoce de los años de juventud de Francisco Heylan en Amberes es que tuvo una amistad con Leonardo Conrrad de profesión bordador quien en la conformación del expediente matrimonial del mayor de los Heylan en 1612, afirmará conocer «... a Francisco // [Fol.4r.] Hilan flamenco, de seis o siete años a esta parte [aproximadamente entre 1605 y 1606 teniendo en cuenta la fecha del testimonio] y lo a tratado de hordinario en Am/beres, en Flandes donde lo començo a conozer» ${ }^{12}$. De dicho testimonio se ponen de manifiesto dos cuestiones; en primer lugar que ésta fue una amistad forjada poco antes de la partida de los hermanos Heylan a la Península; y en segundo lugar que el contacto de los grabadores con Conrrad se mantuvo durante los años de estancia en Andalucía, tanto en Sevilla como en Granada por lo menos hasta la fecha de su testimonio.

7 Expediente matrimonial de Francisco Heylan con doña Ana de Godoy. Granada, 17 de octubre de 1612. Archivo Histórico Diocesano de Granada [AHDGr.]. Serie Expedientes Matrimoniales, Sección Vicaría, Leg. 54/125, Fol. 3v. Cfr. MORENO GARRIDO, 1976, doc. II, pp. 158-161. Expediente Matrimonial de Bernardo Heylan con doña María de las Nieves. Granada, 9 de febrero de 1629. AHDGr. Serie Expedientes Matrimoniales, Sección Vicaría, Leg. 1679, p.6 [1629], Fol. 1v. Cfr. MORENO GARRIDO, Op. cit., 1976, Doc. IV, pp. 161-163.

8 Por el momento no se han podido encontrar documentos que fijen el año de nacimiento de Francisco Heylan.

9 El año de nacimiento de Francisco Heylan fue establecido por el Prof. Moreno Garrido en su tesis doctoral publicada en 1976 El Grabado en Granada... Constituyéndose éste, como el primer dato biográfico del grabador extraído de una fuente documental, que venía a contradecir el año, hasta el momento, propuesto por Hollstein, quien atrasaba el nacimiento del calcógrafo e impresor hasta 1590. HOLLSTEIN, F.W.H.: Dutch and Flemish etchings, engravings and woodcuts ca. 1450-1700. Ámsterdam: Menno Hertzberger, v. 9, 1953, p. 32. El Profesor Moreno acotó dicho año de 1584, a partir del análisis del expediente matrimonial de Francisco Heylan con doña Ana de Godoy -fechado en Granada el 17 de octubre de 1612-, mediante la declaración de los testigos y la propia confesión del contrayente, que fueron claves, para establecer este y otros datos relativos sobre los orígenes del grabador. Cfr. MORENO GARRIDO, Op. cit., 1976, nota n 13, pp. 60-61.

10 Partida de casamiento de Francisco Heylan con Ana de Godoy. Granada a 29 de octubre de 1612. Archivo Iglesia de San Miguel de Granada (AIM). Libro de Matrimonios [1598-1633], fols. 66v.-67r. Cfr. MORENO GARRIDO, Op. cit., 1976, doc. III, p. 161.

11 Expediente matrimonial de Francisco Heylan con doña Ana de... AHDGr. Serie Expedientes Matrimoniales, Sección Vicaría, Leg. 54/125, Fol. 1r. Cfr. MORENO GARRIDO, Op. cit., 1976, Doc. II, pp. 158-161.

12 Ibidem., Fol. 3v.-4r. 
Se ha podido saber a través de un dato obrante en la declaración realizada por el religioso jesuita el Padre Maestro Tomás de León, para la limpieza de sangre de Silvestre Heylan biznieto de Francisco Heylan y nieto de Bernardo Heylan -cuando éste optaba a una plaza de canónigo en el Sacro Monte-, que la familia Heylan procedía de un linaje de nobleza adquirido tiempo atrás por la actuación valerosa de uno de sus antepasados.

«[...] de los Heilanes conoçe muchos caualleros en la Corte de Bruselas de Flandes donde se hallo el año pasado de mil y seisciento y veinte y cinco y supo y oio, como tienen este apellido que en lengua de aquel pais significa libertador, porque en una ocasion libro a un conde de Flandes de un peligro euidente de muerte, y esto a sauido y entendido por los Anales de aquella prouinçia.» ${ }^{13}$.

Esta noticia tiene una gran relevancia si se tiene en cuenta que procede del año 1625, tiempo para el cual Francisco y Bernardo Heylan ya gozaban en Granada de un prestigio y reconocimiento social y profesional importante. A esta reciente averiguación se añaden nuevos aspectos aportados por la declaración de Fray Bernardo de Figueroa, -lector jubilado y definidor de la provincia de los padres terceros de San Francisco y ministro del Convento de San Antonio Abad de Granada-, quien aseguraba que en Flandes esta familia era tenida por hijosdalgo y que contaban con escudo de armas propio.

«[...] estas familias estan tenidos en esta ciudad por hijosdalgo notorios y de mui grande e ilustre sangre como lo significa el escudo de las armas que esta sobre la losa de la sepultura que oi posee dicha familia como consta de una inscripcion que tiene dicha losa que esta en la parrochia de Señora Santa Ana de esta ciudad oradada dicha sepultura de Francisco Heilan visaguelo del pretendiente» ${ }^{14}$.

Los dos hermanos tuvieron que formarse en esta región flamenca donde aprendieron las principales técnicas de grabado conocidas dado el nivel que presentan sus obras ya en 1608. Fue Francisco quién adquirió una singular destreza en el manejo del buril, técnica que empleará durante toda su trayectoria profesional en la Península y por la cual destacó en la primera mitad del siglo XVII. Por el momento no se puede afirmar quién debió ser el maestro de Francisco Heylan, pero la historiografía ${ }^{15}$ ya vino señalando las fuertes influencias que su grabado manifestaba respecto de las estampas de los Wierix, con cuyo taller sería posible relacionarlo debido a la gran

13 Expediente de limpieza de sangre de Silvestre Heylan electo para una canonjía en la Insigne Colegial del Sacro Monte. Granada, 26 de agosto de 1688. AASM. Leg. 129, Fol. 5v..

14 Ibídem., Fol. 17r. A pesar del empeño, ha sido imposible encontrar la sepultura mencionada en los documentos en la parroquia de Santa Ana, debido al revestimiento de madera al que fue sometida toda la iglesia en el siglo XVIII, tabicaje en madera tras el que se debe de encontrar.

15 GÓMEZ MORENO Y MARTÍNEZ, Manuel, «El arte de grabar en Granada». Revista de Archivos, Bibliotecas y Museos, (1900), p. 9; MORENO GARRIDO, Op. cit., 1976, p. 58. 
proximidad que presentan los diseños y la técnica de Francisco practicada en Andalucía ${ }^{16}$.

También en Amberes debió dar sus primeros pasos en el arte de la imprenta ${ }^{17}$. Esta faceta cobrará un renovado significado al enriquecer el perfil profesional de este grabador quién con presteza y versatilidad no sólo abrirá las planchas de cobre y las estampará, sino que también se ocupará, desde el momento en el que disponga de todos los útiles necesarios, de la impresión de los textos donde estas se insertan. De manera que a partir de $1617^{18}$ Francisco Heylan se ocupará en su taller de controlar todo el proceso de elaboración y edición de la obra impresa.

Ya se ha señalado que la posible decisión de Francisco y Bernardo de partir rumbo a la Península estuviese motivada por la búsqueda de nuevos horizontes de trabajo en el arte del grabado donde la demanda de estampas a buril fuese importante. A esta hipótesis se puede sumar el hecho de que para la fecha de su partida 1606 Amberes tuviese un gran número de grabadores experimentados de igual competencia que ellos ${ }^{19}$, de ahí la necesidad de buscar espacios con menos oferta de grabadores donde establecer su taller ${ }^{20}$.

\section{Su primer destino en la Península, Sevilla 1606-1611}

El primer destino de Francisco y Bernardo Heylan, conocido por el momento, fue Sevilla. Tiene sentido la elección de esta ciudad por parte de los dos hermanos, debido al papel determinante que jugó como principal puerto de conexión con Indias donde era importante el flujo de actividad comercial organizado con las nuevas tierras americanas. Los jóvenes reconocen en el expediente matrimonial de Francisco Heylan de octubre de 1612 que ambos «[...] des/embarcaron en la ciudad de Sevilla [...] ${ }^{21}$, suponemos que a finales de $1606^{22}$, ya que ellos mismos aseguran en 1612 que «[...]

16 El planteamiento de esta hipótesis se debe al resultado del análisis practicado en el estudio directo de las estampas de Francisco Heylan y de los Wierix, cuyas conclusiones se ofrecerán en un estudio comparativo posterior.

17 MORENO GARRIDO, Antonio: «La etapa sevillana de Francisco Heylan». En: Cuadernos de Arte de la Universidad de Granada. XVI (1984), p. 350; MORENO GARRIDO, Op. cit., 1976, p. 58.

18 El primer impreso firmado por Francisco Heylan es un folleto de cuatro folios donde se recoge una información relativa a los descubrimientos de las reliquias del Sacro Monte. RELIQUIAS, Relación de las, [Relacion breve de las reliquias que se hallaron en la ciudad de Granada en una torre antiquissima y en las cavernas del monte Illipulitano de Valparayso cerca la ciudad ... . Granada: Francisco Heylan, 1617.

19 Está en elaboración un trabajo que aborda los datos referentes al gremio de grabadores e impresores de la ciudad de Amberes.

20 PÁEZ, Elena, Op. cit., 1952, p. 12; LAFUENTE FERRARI, Op. cit., 1952, pp. 39-40; AINAUD, Op. cit., 1962 , pp. 275-276.

21 Expediente Matrimonial de Bernardo Heylan con... AHDGr. Serie Expedientes Matrimoniales, Sección Vicaría, Leg. 1679, p.6 [1629], Fol. 3r. Cfr. MORENO GARRIDO, Op. cit., 1976, Doc. IV, p. 162.

22 El año de 1606 ya fue propuesto por Moreno Garrido, frente al ofrecido por Hollstein que situaba la llegada de Francisco Heylan a Sevilla en 1608, basándose para ello en las deducciones realizadas a partir de los expedientes matrimoniales de los dos hermanos. HOLLSTEIN, F.W.H., Dutch and Flemish etchings, engravings and woodcuts ca. 1450-1700. Amsterdam: Menno Hertzberger, 1953-1956, t. IX, p 32; MORENO GARRIDO, Op. cit., 1976, Doc. II y IV, pp. 158-163. 
abra seis años que vinieron juntos a Sevilla [...] $\rangle^{23}$, cuando Francisco contaba con 22 años y Bernardo tan solo con 18 años aproximadamente.

Por otro lado se sabe que en Sevilla existió una comunidad alemana y flamenca importante congregada en torno a la Iglesia del Colegio dominico de Santo Tomás de Aquino, donde se encontraba la Capilla de san Andrés dotada por dichas naciones desde $1604^{24}$. Comunidad que inicialmente pudo ejercer cierto amparo a los jóvenes flamencos a su llegada sirviendo de ayuda en su adaptación a este nuevo espacio ${ }^{25}$. Por otro lado parece que esta práctica hospitalaria sería habitual entre compatriotas tal y como nos consta en el caso de Juan Mayor ${ }^{26}$,-futuro marido de Ana Heylan de origen alemán-, quien se alojó en casa de Francisco Heylan a petición de sus propios progenitores porque «[...] era hijo de buenos padres y los conocia, y le encargó a Francisco Hielan inpresor que el mirasse por él, porque se benia de su tierra a esta ciudad y no tenia en ella quien le faboreciese $[\ldots]\rangle^{27}$.

Francisco Heylan debió permanecer en Sevilla durante cinco años aproximadamente, desde finales de 1606 hasta octubre de $1611^{28}$, «[...] donde [vivió] a la collacion de la Magdalena [...]» $\gg^{29}$. Aunque también se ha sabido gracias al testimonio de Leonardo Conrrad que este lo trató durante «año y medio en la parroquia de la Yglesia Mayor [de Sevilla]» ${ }^{30}$. En esta ciudad entrará en contacto con un importante círculo de impresores, literatos, pintores, grabadores, nobles y sobre todo religiosos que darán a su trayectoria profesional un importante impulso, siendo los últimos años vividos en la ciudad hispalense -entre 1609 y 1611- los más destacados de todo el periodo debido al incremento de producción calcográfica que aquí realizó. Tiempo suficiente durante el cual Francisco se fue fraguando su prestigio como uno de los grabadores de estampas finas.

23 Expediente matrimonial de Francisco Heylan con doña Ana de... AHDGr. Serie Expedientes Matrimoniales, Sección Vicaría, Leg. 54/125, Fol. 1r. Cfr. MORENO GARRIDO, 1976, doc. II, p. 158.

24 Fundación del Colegio Mayor de Santo Tomás de Aquino en Sevilla. Archivo General Arzobispado de Sevilla [AGAS]. Seminario. Leg. 241, s.f.

25 El Prof. Moreno cita una serie de trabajos para seguir el rastro de esta afirmación acerca de ese éxodo de artistas flamencos hacia la Península. Entre ellos se cita en el trabajo de CEÁN BERMÚDEZ, Juan Agustín: Diccionario histórico ..., 1800, t. I, pp. 123, 124, 305-307; t. II, pp. 133-134; t. III, pp. 236-237; t. IV, pp. 8793, 113, 251, 357-358; PÁEZ, Elena: Antología del grabado español, quinientos años de su arte en España: Catálogo-guía de la Exposición preparada por la Sección de Estampas bajo la dirección de Elena Páez. Madrid: Hauser y Menet, 1952; LAFUENTE FERRARI, Enrique: «Una antología..., (1952), pp. 35-44; AINAUD, Juan: «Grabado». En: Ars Hispaniae. Historia Universal del Arte Hispánico. Madrid: Editorial Plus Ultra, t. 18, 1962, pp. 275-276. Cfr. MORENO GARRIDO, Op. cit., 1976, nota nº 16, p. 61.

26 Hemos podido certificar este apellido, gracias a un documento en el que le descargan 30 reales a Juan Mayor por el pago de unas rúbricas del Provisor que abrió para acompañar unas cédulas de confesión. Recibi de un pago realizado a Juan Maior, de 30 reales por treinta rúbricas del Provisor abiertas para acompañar Cédulas de confesión. Granada, 24 de marzo de 1640. AHDGr. Libros de Fábrica, Contaduría Mayor, 342-F, p.3, 1640, s.f.

27 Expediente Matrimonial de Anna Heylan con Juan Mayor. Granada, 18 de mayo de 1630. AHDGr. Serie Expedientes Matrimoniales, Sección Vicaría, Leg. 126/11, Fol. 3r.

28 Establecimiento de fecha que posteriormente aclararemos.

29 Expediente matrimonial de Francisco Heylan con doña Ana de... AHDGr. Serie Expedientes Matrimoniales, Sección Vicaría, Leg. 54/125, Fol. 1r. Cfr. MORENO GARRIDO, Op. cit., 1976, Doc. II, p. 158.

30 Ibidem., Fol. 4r. 
Si se contabiliza el número de obras ejecutadas por Francisco Heylan durante los primeros años de estancia en Sevilla, -tomando como referencia exclusivamente el año y localización de las publicaciones donde se encuentran insertas dichas estampas-, se advertirá que entre 1608 y 1611 Francisco realizó un número relativamente importante de grabados, dieciocho en cuatro años: cuatro frontispicios arquitectónicos, dos portadas con heráldica, cinco retratos, un mapa cartográfico, un escudo eclesiástico y otro nobiliario, una alegoría religiosa, un árbol genealógico, una dedicatoria y un retrato de un santo, estampa que recientemente le ha sido atribuida ${ }^{31}$. Creemos que una producción razonable para subsistir los primeros años que vivió en la ciudad del Guadalquivir y lograr una imagen como grabador a buril muy destacable.

Se debe tener en cuenta que la producción de Francisco Heylan realizada desde su llegada hasta la primera obra de él catalogada, deja un margen que no permite establecer con precisión su quehacer durante ese tiempo en Sevilla. Es decir, el primer trabajo de Francisco Heylan en esta ciudad aparece datado en 1608, sin que por el momento se hayan encontrado noticias de otros grabados anteriores, ni si quiera durante su periodo de formación en Amberes. En este año aparece firmada la estampa encargada para el convento de los franciscanos, grabado para el que abrió dos matrices. Una de ellas de grandes dimensiones, cuya composición fue inventada por Fray Juan Jiménez, teólogo del Colegio de San Buenaventura de Sevilla que representa $E l$ abrazo de Cristo y San Francisco, y el árbol de la Familia Franciscana (fig. 1) y otra de menor tamaño donde se incorpora una laudatoria hacia Fray Pedro González de Mendoza, quien por entonces ejercía las funciones de General y Comisario de la Orden franciscana. La estampa, de la que Moreno Garrido sólo obtuvo noticias a nivel documental ${ }^{32}$, ha sido dada a conocer en un estudio reciente ${ }^{33} \mathrm{y}$ aparece del siguiente modo firmada:

«f. Joanes Ximénes Lector Theologus in Hispalensi Collegio seraphici D.S. Bonaventurae inventor FRANUS. HEYLAN Antverpensis sculpsit, Hispali anno 1608».

Esto nos lleva a la conclusión de que el trabajo realizado por Francisco Heylan como grabador en Sevilla y por tanto el balance que se debe de realizar sobre la obra del artista catalogada en esta ciudad, ha de ser evaluado en su justa medida dentro de los cuatro años de producción registrados que van desde 1608 a 1611, en vez de contabilizar su labor desde el año de su llegada a Sevilla en 1606.

31 El catálogo razonado con toda la obra de Francisco Heylan se encuentra en mi tesis doctoral: Los descubrimientos del Sacro Monte ..., 2014.

32 Así señalaba Moreno Garrido el conocimiento de la primera obra grabada por Francisco Heylan en Sevilla «La primera obra, de la que tenemos sólo referencia, es una realizada por J. Joannes Ximenes Lector Theologus in hispalensi Collegio Sefaphico D. S. Bonaventurae. Así reza en la lámina de un "Árbol genealogico cristiano donde los grandes santos de los dos sexos en la gradas de gloria espiritual en la luz que radian del Espiritu Santo. Al pie del árbol se ve a S. Francisco abrazando a Cristo; a los lados de la estampa figuran dos padres de la Iglesia más grandes que las otras personas y presentas máximas religiosas sobre filacterias"». Cita que aunque no indica de donde está tomada creemos que se corresponde con la descripción que realiza Hollstein del mismo. Cfr. MORENO GARRIDO, Op. cit., 1984, p. 355; HOLLSTEIN, Op. cit., 1953, v. IX, p. 276.

33 PÉREZ GALDEANO, Op. cit., 2014, vol. 4, parte 1, pp. 15-27. 


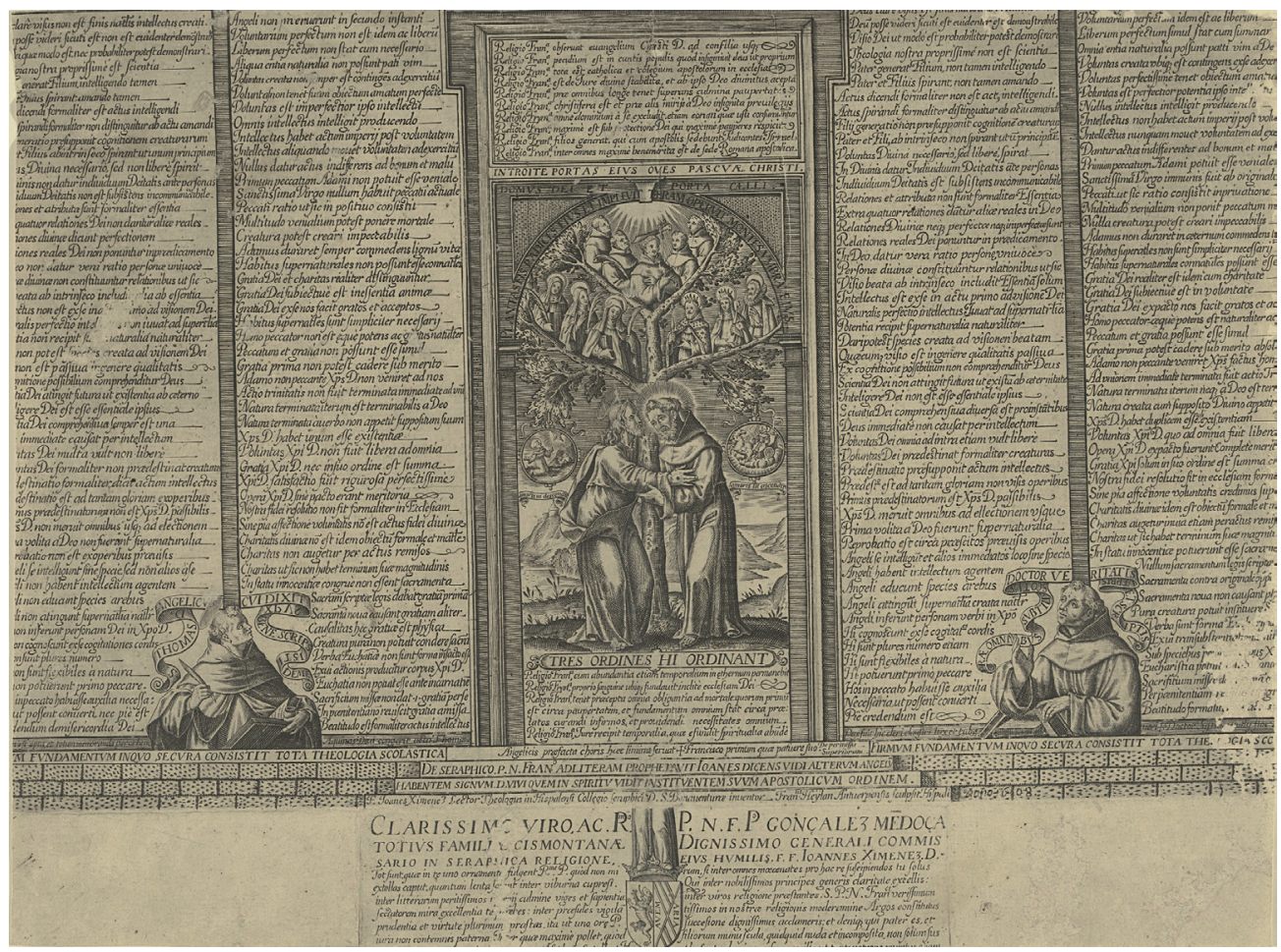

Fig. 1. Francisco Heylan, El abrazo de Cristo y San Francisco, y el árbol de la Familia Franciscana. Talla dulce, 1608, [F. Joanes Ximénez Lector Theologus in Hispalensi Collegio Seraphici D.S. Bonaventurce inuentor / Fran ${ }^{u s}$ Heÿlan Antuerpensis sculpsit Hispali anno 1608]. Hoja 297 x 399 mm. (C) Rijksmuseum, Amsterdam, RP-P-1878-A-1034.

Sin embargo se debe señalar que en 1612, año en el que encontramos plenamente establecido a Francisco en Granada, encontramos cinco estampas más publicadas en impresos sevillanos. Este hecho nos lleva a preguntarnos isi dichas matrices fueron abiertas en Granada o en Sevilla? O en su caso lleva a preguntarnos, si Francisco debió de estar un tiempo itinerante entre Sevilla y Granada. Posibilidad remota que no se debería descartar. Sin embargo, según el análisis de los datos y obras estudiadas, todo nos lleva a pensar que las planchas de estas cinco estampas pudieron ser abiertas en Granada aunque su encargo bien pudiera ser realizado cuando Francisco todavía se encontraba en Sevilla. No olvidemos que el grabador ya gozaba de un prestigio en su arte y que su traslado a la ciudad de la Alhambra no debió ser ningún obstáculo. 


\section{Su traslado y definitivo asentamiento en Granada, 1611-1635}

La llegada de Francisco Heylan a Granada en 1611, se ha venido vinculando tradicionalmente $^{34}$, al encargo que el flamenco recibió por parte de Justino Antolínez, Provisor y mano derecha del arzobispo de Granada Don Pedro de Castro, para la ilustración de su Historia Eclesiástica de Granada ${ }^{35}$ (fig. 2).

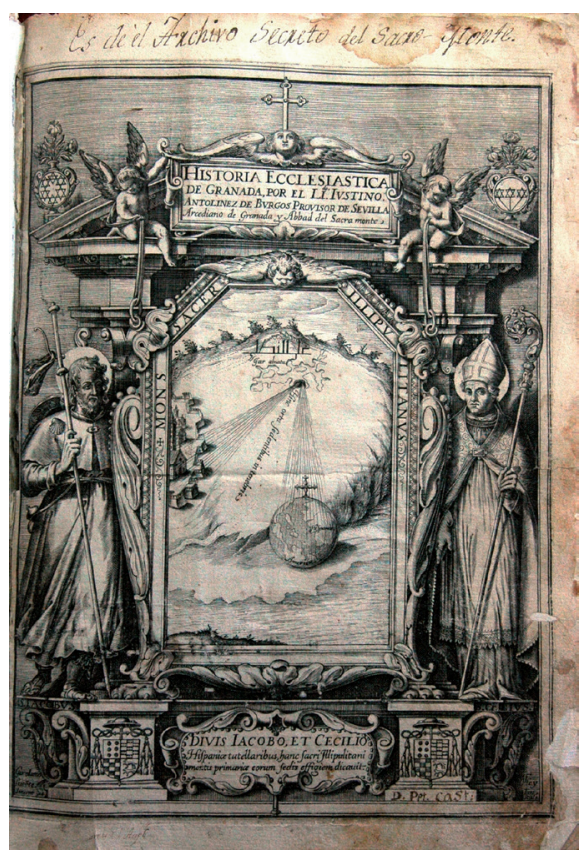

Fig. 2. Francisco Heylan, Portada arquitectónica: Santiago Apóstol, San Cecilio y las cavernas del Sacro Monte iluminando el orbe católico. Talla dulce, 1611, [Girolamo Lucēte invent. / F. Hey/lan Sculp.]. Huella 270 x 198 mm. En: ANTOLÍNEZ, Justino: Historia Eclesiástica de Granada. Manuscrito, 1610. (C) MASM. C-2.

34 Moreno Garrido fue quién más aproximó el año de llegada de Francisco Heylan según la propuesta que en este estudio se hace, situándolo en Granada hacia finales de 1611. Mientras que Gómez Moreno Martínez emplazaba dicho traslado hacia 1613. MORENO GARRIDO, Op. cit., 1976, p. 58; GÓMEZ MORENO MARTÍNEZ, Op. cit., 1900, p. 9.

35 Se tiene constancia de la existencia de al menos un ejemplar hológrafo de la obra de Antolínez conservado en la Biblioteca del Hospital Real de Granada, ANTOLÍNEZ DE BURGOS, Justino: Historia Eclesiástica de Granada. [Manuscrito], [Granada: s.n., s.a., 1610]. BHR/caja MS-1-049 [Olim. BHR/Caja B-032]. Otro ejemplar preparado para la edición, pero falto de la tercera parte de la obra que se conserva en el Museo de la Abadía del Sacro Monte. Además se cuenta con una copia manuscrita del siglo XVII, conservada también en la Biblioteca del Hospital Real de Granada, ANTOLÍNEZ DE BURGOS, Justino: Historia Eclesiástica de Granada. Manuscrito [copia] [Granada: s.n., s.a. [16??]]. BHR/Caja MS-2-044 [Olim. BHR/Caja C-073]. Todo ello sin olvidar los borradores incompletos hológrafos de Antolínez que se encuentran en el legajo 3 de los documentos de don Pedro conservados en el Archivo de la Abadía del Sacro Monte [AASM. Leg. 3, I parte]; así como en el legajo 145 de esta misma colección documental en el Archivo de la Abadía del Sacro Monte [AASM. Leg. 145], entre otros. 
Obra que recogía los descubrimientos de las reliquias y libros plúmbeos que tanto conmocionaron a las autoridades eclesiásticas, civiles y a la ciudad entera en los últimos años del siglo XVI ${ }^{36}$. Este importante proyecto editorial hacía imprescindi-

\footnotetext{
36 Existe una variada bibliografía al respecto de los Descubrimientos del Sacro Monte de la cual queremos hacer mención, dada la importancia de la temática en los estudios de investigación actuales. ROYO CAMPOS, Zótico: Reliquias martiriales y escudo del Sacro-Monte. Granada: Abadía del Sacro-Monte, 1960. Obra reeditada por la Universidad de Granada en 1995, con un estudio crítico preliminar a cargo del historiador Miguel Luis López Guadalupe. CABANELAS RODÍGUEZ, Darío: El morisco Alonso del Castillo. Granada: Patronato de la Alhambra y Generalife, 1965. ROYO CAMPOS, Zótico: Reliquias martiriales y escudo del Sacro-Monte. Edición facsímil. Estudio preliminar por Miguel L. López Muñoz. Granada: Universidad de, 1995, pp. LXX-LXXI. MARTÍN PALMA, José: La última crisis de la Abadía del Sacromonte. Veinticinco años de historia (1950-1975). Granada: Ave María, 1995. SÁNCHEZ OCAÑA, Juan: El Sacro Monte de Granada: imaginación y realidad. Granada: Ayuntamiento de, 2007. GODOY ALCÁNTARA, José: Historia crítica de los falsos cronicones. Madrid: Real Academia de la Historia, M. Rivadeneyra, 1868. Con una edición facsímil publicada en 1999, con un estudio preliminar de Ofelia Rey Castelao. Autora de otro estudio de igual contenido en REY CASTELAO, Ofelia: «La Historia crítica de los falsos cronicones de José Godoy Alcántara». En: ¿La historia inventada?: Los libros plúmbeos y el legado sacromontano. BARRIOS AGUILERA, Manuel y GARCÍA-ARENAL, Mercedes (editores). Granada: Universidad de; el Legado Andalusí, 2008, pp. 395-436. GÓMEZ DE LIAÑO, Ignacio: Los juegos del Sacromonte. Madrid: Editora Nacional, 1975. Obra que fue publicada por la Universidad de Granada en 2005 en edición facsímil, con un estudio preliminar de Manuel Barrios Aguilera y García Álvarez. ALONSO, Carlos: Los Apócrifos del Sacromonte (Granada). Estudio histórico. Valladolid: Estudio Agustiniano, 1979. HAGERTY, Miguel José: Los libros plúmbeos del Sacromonte. Madrid: Editora Nacional, 1980. CARO BAROJA, Julio: Las falsificaciones de la Historia (en relación con las de España). Barcelona: Seix Barral, 1992. VAA.VV: Jesucristo y el emperador cristiano: Catálogo de la exposición celebrada en la Catedral de Granada con motivo del año jubilar... y del V Centenario del nacimiento del emperador Carlos: Granada, 8 de julio al 8 de diciembre / edición a cargo de MARTÍNEZ MEDINA, Francisco Javier; [organiza Arzobispado de Granada]. Córdoba: Obra social y cultural Cajasur, 2000. BARRIOS, Manuel: «Moriscos y cristianos en el orto de la Granada moderna». En: Jesucristo y el Emperador cristiano (Catálogo de la exposición celebrada en la Catedral de Granada, con motivo del año jubilar de la Encarnación de Jesucristo y del V Centenario del nacimiento del emperador Carlos. Edición a cargo de F. J. Martínez Medina. Córdoba: Caja Sur, 2000, pp. 601-617; BARRIOS, Manuel: «El Albaicín de Granada sin moriscos. Memoriales para su restauración», Chronica Nova, 23(1996), pp. 439-463; BARRIOS, Manuel: «Tesoros moriscos y picaresca», Espacio, Tiempo, Forma. Serie IV, 9 (1996), pp. 11-24; BARRIOS, Manuel: «Misiones del Sacromonte de Granada al Arzobispado de Sevilla. Relato documental». En: Homenaje a don Antonio Domínguez Ortiz (Juan Luis Castellano Castellano, ed.). Granada: Universidad de, 2006. Entre otros muchos estudios que dejo sin nombrar. BARRIOS, Manuel: Los falsos cronicones contra la historia (o Granada, corona martirial). Granada: Universidad de, 2004; BARRIOS, Manuel: «Don Pedro de Castro y el Sacromonte de Granada en el "Místico ramillete" de Heredia Barnuevo (1741)». En: HEREDIA BARNUEVO, Diego Nicolás. Místico ramillete. Vida de D. Pedro de Castro, fundador del Sacromonte.Granda: Universidad de, 1998, pp. VIILXXIV + álbum de 41 ilst.; BARRIOS, Manuel: «Las invenciones del Sacromonte. Estado de las cuestiones y últimas propuestas». En: GÓMEZ DE LIAÑO, Ignacio. Los Juegos del Sacromonte. Granada: Universidad de, 2005, pp.VII -LIII; BARRIOS, Manuel: «Pedro de Castro y los Plomos del Sacromonte: invención y paradoja. Una aproximación crítica». En: Los plomos del Sacromonte: invención y tesoro. BARRIOS AGUILERA, Manuel y GARCÍA-ARENAL, Mercedes (editores). Valencia: Universidad de; Granada: Universidad; Zaragoza: Universidad de, 2006, pp. 17 -50; BARRIOS, Manuel: «El castigo de la disidencia en las invenciones plúmbeas. Sacromonte versus Ignacio de las Casas (edición revisada)». En: Los plomos del Sacromonte: invención y tesoro. BARRIOS AGUILERA, Manuel y GARCÍA-ARENAL, Mercedes (editores). Valencia: Universidad de; Granada: Universidad; Zaragoza: Universidad de, 2006, pp. 481-520; BARRIOS, Manuel: «Claves de la historia laminaria en la formación y edición de 'Vindicias Catholicas Granatenses'. ¿Una cuestión regalista?». En: Homenaje a la profesora María Isabel Pérez de Colosía (Juan Jesús Bravo Caro, ed.). Málaga, 2006; BARRIOS, Manuel: «Granada en escorzo. Luis Francisco de Viana y la historiografía del Sacromonte». Demófilo. Revista de cultura tradicional de Andalucía, 35 (2000), pp. 45-80; BARRIOS, Manuel: «El bucle metahistórico. Los libros plúmbeos de Granada, realidad histórica y mito». Fundamentos
} 
ble, debido a la trascendencia de los descubrimientos y el proyecto que a estos les acompañaba, disponer de unas manos expertas que ilustraran por medio del grabado en hueco un discurso histórico de marcado carácter apologético ${ }^{37}$. Estampas más acordes con el gusto de la época abiertas bajo la influencia de la estética manierista de corte flamenco. Esta empresa para la que Francisco abrió 28 planchas tamaño folio y cuatro de gran formato se dilató en el tiempo, desde 1612 hasta 1624, quedó finalmente sin publicar permaneciendo sus estampas al alcance de un reducido número de personas influyentes. Esto hará que el grabador no fuese admirado por su participación en dicha obra, pues ésta no llegó a ver la luz, sino que tendría que esperar a la participación en un segundo gran proyecto editorial, como fue la ilustración de la Historia del Monte Celia de Nuestra Señora de la Salceda ${ }^{38}$, escrita por Fray Pedro

de Antropología, 10-11 (2001), pp. 321-333; BARRIOS, Manuel: «El castigo de la disidencia en las invenciones plúmbeas de Granada. Sacromonte versus Ignacio de las Casas». Al-Qantara, XXIV-2 (2003), pp. 477-532; BARRIOS, Manuel: «Ignacio de las Casas y la polémica laminaria en la Historia authéntica de Viana y Laboraría. El texto». Chronica Nova, 29 (2002), pp. 343-405; BARRIOS, Manuel y GARCÍA ARENAL, Mercedes: «Los libros plúmbeos de Granada: nueva cita, nuevas propuestas». En: ¿La historia inventada?: Los libros plúmbeos y el legado sacromontano. BARRIOS AGUILERA, Manuel y GARCÍA-ARENAL, Mercedes (editores). Granada: Universidad de; el Legado Andalusí, 2008, pp. 9-28; BARRIOS, Manuel: «Claves de la historia laminaria en la formación y edición de Vindicias Catholicas Granatenses». En: ¿La historia inventada?: Los libros plúmbeos y el legado sacromontano. BARRIOS AGUILERA, Manuel y GARCÍA-ARENAL, Mercedes (editores). Granada: Universidad de; el Legado Andalusí, 2008, pp. 347-374; BARRIOS AGUILERA, Manuel: La invención de los libros plúmbeos. Fraude, historia y mito. Granada: Editorial Universidad de, 2011. GARCÍA-ARENAL RODRÍGUEZ, Mercedes y RODRÍGUEZ MEDIANO, Fernando: «Médico, traductor, inventor: Miguel de Luna, cristiano arábigo de Granada». Chronica Nova, 32 (2006); GARCÍA-ARENAL RODRÍGUEZ, Mercedes: «El entorno de los Plomos: historiografía y linaje». En: Los plomos del Sacromonte: invención y tesoro. BARRIOS AGUILERA, Manuel y GARCÍA-ARENAL, Mercedes (editores). Valencia: Universidad de; Granada: Universidad; Zaragoza: Universidad de, 2006, pp. 51-78; GARCÍA-ARENAL RODRÍGUEZ, Mercedes: «De la autoría morisca a la antigüedad sagrada de Granada, rescatada al Islam». En: Los plomos del Sacromonte: invención y tesoro. BARRIOS AGUILERA, Manuel y GARCÍA-ARENAL, Mercedes (editores). Valencia: Universidad de; Granada: Universidad; Zaragoza: Universidad de, 2006, pp. 557-582; RODRÍGUEZ MEDIANO, Fernando y GARCÍA-ARENAL RODRÍGUEZ, Mercedes: «De Diego de Urrea a Marcos Dobelio, intérpretes y traductores de los 'Plomos'». En: Los plomos del Sacromonte: invención y tesoro. BARRIOS AGUILERA, Manuel y GARCÍA-ARENAL, Mercedes (editores). Valencia: Universidad de; Granada: Universidad; Zaragoza: Universidad de, 2006, pp. 297-334; GARCÍA-ARENAL RODRÍGUEZ, Mercedes y RODRÍGUEZ MEDIANO, Fernando: «Jerónimo Román de la Higuera and the Lead Books of the Sacromonte». The Conversos and Moriscos in Late Medieval Spain and Beyond. E.J. Brill, 2009. GARCÍA-ARENAL RODRÍGUEZ, Mercedes y RODRÍGUEZ MEDIANO, Fernando: «Los libros de los moriscos y los eruditos orientales». Al-Qantara, XXXI, 2 (2010); GARCÍA-ARENAL RODRÍGUEZ, Mercedes: «Miguel de Luna y los moriscos de Toledo: "no hay en España mejor moro"». Chronica Nova, 36 (2010); GARCÍA-ARENAL, Mercedes; RODRÍGUEZ MEDIANO, Fernando: Un Oriente español. Los moriscos y el Sacromonte en tiempos de Contrarreforma. Madrid: Marcial Pons Historia, 2010.

37 Esta idea ya la avanzó Moreno Garrido en el adelanto que publicó de su tesis doctoral, MORENO GARRIDO, Antonio: «El grabado en el Sacromonte». En: La Abadía del Sacromonte. Exposición artísticodocumental. Estudios sobre su significación y orígenes. Granada: Universidad, 1974.

38 MARÍAS FRANCO, Fernando: «El verdadero Sacro Monte, de Granada a La Salceda, Don Pedro González de Mendoza, Obispo de Sigüenza, y el Monte Celia». Anuario del Departamento de Historia y Teoría del Arte, 4 (1992), pp. 133-144; FERNÁNDEZ MADRID, María Teresa; GÓMEZ LORENTE, Manuel: «El convento de Nuestra Señora de la Salceda análisis histórico y simbólico». Wad-al-Hayara: Revista de estudios de Guadalajara, 19 (1992), pp. 431-444. 
González de Mendoza e impresa en Granada en 1616, para manifestarse como un importante grabador de esta ciudad.

El arte de la imprenta, sobre todo el que estuvo vinculado a Granada a través de la Real Chancillería, va a encontrar en la persona de Francisco a alguien capaz de asumir un campo poco explotado por ésta en el ámbito de la documentación jurídica, a la que el grabador le aportará su impronta personal con la incorporación de estampas xilográficas o calcográficas en la mayoría de sus impresos. Esta labor amplificará su actividad productiva, tanto en el ámbito de los impresos como en el del grabado, lo que le reportará una estabilidad profesional al grabador y a su taller durante un largo periodo ${ }^{39}$. Este giro profesional hacia una especialización en el arte de la impresión, que Francisco Heylan desarrollará a partir de $1617^{40}$, se deberá entender como un esfuerzo por afianzarse profesionalmente y vivir con cierta independencia de los trabajos esporádicos que el grabado le estaba proporcionando. Ocupación la de impresor que compaginó con gran éxito junto con su faceta de grabador. También debemos señalar que su vinculación con el panorama tipográfico sevillano nunca se llegará a perder, es más, serán numerosas las colaboraciones de carácter calcográfico que continuará elaborando el flamenco a lo largo de su vida para este importantísimo espacio de producción. Tanto es así que se ha podido contabilizar una producción total de unas diecisiete estampas a partir de 1612: las cinco ya mencionadas en ese año; cinco estampadas en 1615; dos estampas atribuidas en 1612; una firmada y otra atribuida en 1619; una firmada en 1621; otra en el año de 1626 y finalmente una atribución de 1633.

Ya se ha indicado que fue Moreno Garrido quien estableció la llegada de Francisco Heylan a Granada hacia finales de $1611^{41}$. Pero es posible concretar aún más el momento en el que se produjo dicho traslado y fijarlo en el mes de octubre de dicho año, si se tiene en cuenta el testimonio de dos declarantes que participaron en el expediente matrimonial del flamenco fechado en octubre de 1612. El primero es Leonardo Conrrad, quien informó acerca de su reencuentro con Francisco Heylan en Granada por el mes de mayo de 1612:

39 El periodo de trabajo del taller tipográfico de Francisco Heylan que se ha podido registrar nos lleva a unos quince años de existencia que abarca desde 1617 con el primer impreso por ahora constatado y 1632 inclusive. Es cierto que otros estudios anteriores a este (Gutiérrez del Caño, 1899, pp. 78-79; Izquierdo, 1975; Porro Herrera, 1977, pp. 263-264; Riaño, manuscrito) establecieron una cronología mucho más amplia. Pero finalmente, al no haber podido verificar la existencia de dichos impresos para señalar el periodo cronológico que aquí establecemos, nos hemos basado en nuestros propios resultados alcanzados tras la realización de varios vaciados sistemáticos y el hallazgo de diferentes documentos de archivo. No obstante se puede encontrar las distintas cronologías propuestas y la bibliografía referenciada en LÓPEZ HUERTAS, María José, Bibliografía de impresos granadinos de los siglos XVII y XVIII. Granada: Universidad de, vol. 1, 1997, pp. 134-140.

40 En este año se encuentran localizados los dos primeros impresos de Francisco Heylan. GALVARRO, y Armenta, Juan (O.S.A): Sermon que predicó el padre ... Fray Iuan Galvarro en las honras del Padre ... Fr. Alonso de Villanueva ..., Granada: Francisco Heylan, 1617. BGUS. A. 113/080(15). [Cat.12-1]; RELIQUIAS, Relacion de las: [Relacion breve de las reliquias que se hallaron en la ciudad de Granada en una torre antiquissima y en las cavernas del monte Illipulitano de Valparayso cerca la ciudad ...]. Granada: Francisco Heylan, 1617. BNE. Mss/6437.

41 MORENO GARRIDO, Op. cit., 1976, p. 58 
«abra cinco o seis meses [desde octubre de 1612] que este testigo vino a Granada [es decir, en mayo de 1612] y hallo en ella, en el Monte Santo donde trauaja al dicho Francisco Yelan. Y quando le vido en Granada [mayo de 1612] abria un año que no le be ya, y no saue si este tiempo a estado en Granada adonde» ${ }^{42}$.

El testimonio de Conrrad certifica que Francisco Heylan estaba viviendo en Granada al menos desde mayo de 1612. La segunda declaración que informa al respecto pertenece a Bernardo Heylan y es mucho más decisiva que la anterior para esclarecer las incertidumbres planteadas en el testimonio de Conrrad con respecto al momento desde el que Francisco se instala en Granada. Así dice Bernardo: «... que abra un año que el dicho su hermano está y bibe en Granada a San Saluador ${ }^{43}$. En conclusión, si el testimonio de Bernardo se formuló el 17 de octubre de 1612, quiere decir que Francisco Heylan estaba residiendo en Granada al menos desde octubre de 1611. Por lo tanto la precisión que se hace respecto al mes de su llegada concluimos que fue el de octubre.

Será en esta ciudad de Granada donde Francisco Heylan contraiga también matrimonio con doña Ana de la Paz Estébanez ${ }^{44}$ el 29 de octubre de $1612^{45}$ en la parroquia de san Miguel situada en el barrio del Albaycín. Cuando por entonces Francisco contaba con 28 años de edad y Ana de la Paz, 23.

Doña Ana de la Paz de Hurtado Estébanez o doña Ana de Godoy, como también será mencionada en las fuentes documentales, fue hija de Martín Alonso de Hurtado Estébanez y María Chuezos. Es muy probable que Ana fuese bautizada en la parroquia de San Juan en Lorca (Murcia) en 1589. Al menos así lo deja entrever el testimonio de Magdalena de Yuste, natural de Lorca, quien dijo conocer «... a doña Ana de Godoy de trece años a esta parte [es decir desde 1599]. Y la a tratado de hordinario primero en Lorca a San Juan ${ }^{46}$. Nació en el seno de una familia acomodada procedente de Baza ${ }^{47}$, con posesión de un mayorazgo en la ciudad de Lorca ${ }^{48}$. En esta ciudad pasó su niñez ${ }^{49}$, y fue hacia 1608 cuando la joven, que contaba con 19 años de edad, se trasladó a Grana-

42 Expediente matrimonial de Francisco Heylan con doña Ana de... AHDGr. Serie Expedientes Matrimoniales, Sección Vicaría, Leg. 54/125, Fol. 3v.-4r. Cfr. MORENO GARRIDO, Op. cit., 1976, Doc. II, p. 158 .

43 Ibid.

44 Entre el 17 y el 24 de octubre de 1612, se realiza el expediente matrimonial entre Francisco Heylan y Ana de la Paz Estébanez. Las amonestaciones se dispusieron en las parroquias de san Miguel y del Salvador de Granada. Partida de casamiento de Francisco Heylan con Ana de Godoy. Granada a 29 de octubre de 1612 Archivo Iglesia de San Miguel de Granada (AIM). Libro de Matrimonios [1598-1633], fols. 66v.-67r. Cfr. MORENO GARRIDO, Op. cit., 1976, Doc. III, p. 161.

45 El 29 de octubre de 1612 se celebrará el matrimonio con Ana Godoy Estébanez en la parroquia de San Miguel, Granada. Expediente matrimonial de Francisco Heylan con doña Ana de... AHDGr. Serie Expedientes Matrimoniales, Sección Vicaría, Leg. 54/125, Fol. 1r. Cfr. MORENO GARRIDO, op. cit., 1976, Doc. II, p. 158.

46 Ibidem., Fol. 3r.

47 Expediente de limpieza de sangre de Silvestre Heylan... AASM. Leg. 129, Fol. 7r.

48 Ibídem., Fol. 11v.

49 Sobre su niñez nos dice «Catalina Ximenez de Chueços, ... biuda de Christobal de Pasalagua, almoxarife reçetor del aduana de la ciudad de Lorca» y tía de la joven que « nacio y la a tratado de hordinario en la ciudad de Lorca toda su vida y asta que abra quatro años que se binieron a esta ciudad y la a tratado de hordinario en ella en su casa». Expediente matrimonial de Francisco Heylan con doña Ana de... AHDGr. Serie Expedientes Matrimoniales, Sección Vicaría, Leg. 54/125, Fol. 2v. Cfr. MORENO GARRIDO, 1976, doc. II, p. 159. 
da junto con toda su familia. Y aquí residió como vecina de la parroquia de San Miguel en el barrio del Albaycín ${ }^{50}$.

Francisco y Ana contrajeron matrimonio muy temprano, tan solo un año después de la llegada de Francisco Heylan a la ciudad en el mes de octubre de 1611. Cuatro hijos serán el fruto de este enlace. En 1615 nació su primogénita Ana Heylan, quien se convertirá en la primera grabadora burilista andaluza, cuando su madre contaba con 26 años de edad. Se ha podido saber que la pequeña sería bautizada el 7 de julio de 1615 en la Parroquia de San Juan de los Reyes en Granada ${ }^{51}$. Probablemente en esa fecha la familia decidiera trasladarse desde el alto Albaycín a la parte baja, concretamente a la calle del pan, donde a su padre le veremos firmar numerosos impresos a partir de 1617. Tres años después del nacimiento de Ana Heylan, en 1618 debió nacer su segunda hija María y cinco años más tarde hacia 1623, nacería su tercera hija Elena ${ }^{52}$. El cuarto hijo de Francisco Heylan, un varón al que no se le dio nombre, debió nacer el 26 de octubre de 1625 , pero el pequeño tuvo que nacer muerto o morir al poco de nacer, ya que fue enterrado al día siguiente, el 27 de ese mes en la Parroquia de Santa Ana donde la familia ya contaba con una sepultura en propiedad ${ }^{53}$. Pero esta no sería la única pérdida repentina que sufrirá Francisco Heylan en este año. Tan sólo unos días después del entierro de su hijo, murió su esposa cuando ésta tan sólo contaba con 36 años de edad, probablemente por no poder superar las secuelas del parto. Doña Ana de Godoy sería enterrada junto a su pequeño en la misma parroquia de Santa Ana, el viernes 31 de octubre de $1625^{54}$ en la sepultura familiar.

Acerca de la posesión de dicha sepultura en esta parroquia se ha conocido documentalmente su existencia gracias a los testigos que declararon en la limpieza de sangre de Silvestre Heylan, biznieto de Francisco Heylan y Doña Ana de Godoy, los cuales declararon que

«el dicho Francisco Heilan su visaguelo compró una sepultura, que [aun] oi [en 1688] poseen sus descendientes en la Yglesia Parroquial de // Nuestra Señora Santa Ana de esta ciudad la qual tiene grauadas las armas del suso dicho y de doña Ana Hurtado Esteuanez, su muger como consta de la inscripcion sobre puesta en la losa de la sepultura, en que declara el origen de su naturaleça» ${ }^{55}$.

50 Todos los testigos de la joven aseguran que hacía cuatro años que la joven residía en Granada con toda su familia como vecina de la parroquia de san Miguel. Ibidem., Fol. 2r.-3r. Cfr. MORENO GARRIDO, 1976, doc. II, p. 159.

51 Partida de bautismo de Anna Heylan. AHDGr. Granada a 7 de junio de 1615. Archivo de la Iglesia de San Juan de los Reyes de Granada (AIJRR), Libro de bautismos, Micro N 1327154 IT 7-10.

52 Datos que se han deducido a partir de los escritos de Las Fundaciones de la Madre Antonia de Jesús, donde la beata relata la entrada de las jóvenes hijas de Francisco Heylan al beaterio vinculado al convento de Santo Tomas de Villanueva de la orden agustina situado en el Albaycín. BOHÓRQUEZ JIMÉNEZ, Domingo: Fundaciones femeninas andaluzas en el siglo XVII: Los escritos de la recoleta Madre Antonia de Jesús. Cádiz: Conventos RR.MM Agustinas Recoletas, 1995, pp. 30; 42-45.

53 Partida de defunción del hijo recién nacido de Ana de Godoy y Francisco Heylan. Granada, a 27 de octubre de 1625. AHDGr. Libro de defunción de la Parroquia de Santa Ana, Micro. 1297423/5, fol. 140r.

54 Partida de defunción de Ana de Godoy y Estébanez. Granada a 31 de octubre de 1625. AHDGr. Libro de defunción de la Parroquia de Santa Ana, Micro. 1297423/5, fol. 170v.

55 Expediente de limpieza de sangre de Silvestre Heylan... AASM. Leg. 129, Fol. 7r.-7v. 
Sin embargo, ha sido imposible encontrar la sepultura que se menciona en los documentos debido a las severas transformaciones a las que fue sometido dicho templo en el siglo XVIII, al practicarle un revestimiento de madera a las paredes y capillas laterales más acorde con el gusto de la época. Capa de madera tras el que debe encontrarse dicho enterramiento siempre y cuando este no hubiese sido trasladado o eliminado.

De modo que el último periodo de la década de los años veinte fueron algo complicados para la familia Heylan. Fue una etapa marcada por la pérdida de seres queridos y por la incorporación de nuevos miembros a ésta.

Tras la muerte de doña Ana de Godoy, las tres hijas pequeñas de Francisco Heylan, que por entonces contaban, Ana de 10 años, María de 7 años y Elena con 2, quedaron huérfanas de madre y su padre se encontraba sumido en un trasiego de encargos tipográficos a los que el taller debía dar respuesta. Se han podido contabilizar un total de veintidós impresos firmados sólo en el año de 1626, de lo que se deduce que tras esta significativa pérdida el trabajo mantuvo muy ocupado al impresor. De estos veintidós impresos salidos del taller de los Heylan once se ilustraron xilográficamente, siete con grabados calcográficos empleados con anterioridad, dos aparecen sin ilustrar, uno del que sólo se tiene noticias a través de referencias bibliográficas, un grabado calcográfico nuevo abierto por Bernardo Heylan y un grabado nuevo abierto por el propio Francisco. Durante este periodo, 1625 al 1627, se evidencia una reducción en el número de matrices abiertas a buril que no alcanzarán un número máximo de dos piezas por año. Este descenso en su producción calcográfica puede indicar que Francisco se vería notablemente afectado por los acontecimientos. El hecho de que la imprenta de los Heylan no notase tanto este descenso se puede deber a que dicho taller contaba con la colaboración de al menos dos personas más que le ayudaban en esta tarea; uno era su hermano Bernardo Heylan, de quién se conoce un impreso firmado en 1622 como impresor ${ }^{56}$; y el otro oficial sería el impresor Andrés López quien empezó a trabajar con los Heylan en torno a $1624^{57}$, año que coincide con el aumento de producción de dicho taller.

La responsabilidad de Francisco para con su taller limitaría sobre manera el tiempo del que el grabador dispondría para la atención de las pequeñas tras la pérdida de la madre. De manera que para el cuidado y crianza de sus hijas tuvo que contar con la ayuda de una nodriza. Catalina Juares sería la encargada de ejercer tal ocupación. Una joven de 23 años natural de la villa de Yestes en tierras de Albacete perteneciente al arzobispado de Toledo. Se ha sabido que Catalina debió nacer en torno a 1602 y que vivió su más tierna infancia en casa de sus padres Simón Juares y María de Cozar, y con su hermano Francisco Juares ${ }^{58}$. Es posible que sus progenitores murieran de forma temprana ya que en la documentación encontrada se menciona que fue su hermano Francisco Juares quien se hizo cargo de su crianza hasta cumplir los veinte años de edad ${ }^{59}$. En torno a

56 MONTERREY, Conde de, [Carta de como el Conde de Monterrey desembarcò en Ciuita Vieja, y el recebimiento q[ue] se le hizo en Roma, hallandose en la canonizacion de San Isidro, S. Ignacio, S. Francisco Xauier, santa Teresa, y S. Felipe de Neri : ponense tambien las libreas que los caualleros españoles sacaron este dia]. Granada: Bernardo Heylan, 1622. ARAH. 9/3691(83).

57 Expediente Matrimonial de Francisco Heylan con Catalina Juares. Granada a 26 de junio 1629. AHDGr. Serie Expedientes Matrimoniales, Sección Vicaría, Leg. 121/180, fol. 2v.

58 Ibidem., fol. 1r.

59 Ibid. 
1625 llegó Catalina a Granada procedente de Murcia donde estuvo residiendo en casa de Juan de Messa, sacristán de la iglesia de san Andrés de dicha ciudad desde $1623^{60}$. La joven Catalina se puso al servicio de la familia Heylan tras la inmediata muerte de doña Ana de Godoy y ejerció como ama de cría al menos durante cuatro años. En 1629 Francisco tomará una trascendental decisión con respecto a la joven al pedirle en matrimonio cuando esta ya contaba con 27 años de edad. Conjeturamos que tal decisión pudo estar motivada por dos razones; en primer lugar como fruto de la natural convivencia mantenida durante los cuatro años que la joven estuvo al servicio de Francisco; en segundo lugar, producto de la necesidad de amparo de sus hijas al presentir el grabador que su salud se iba debilitando y que su ausencia podría generar la indefensión total de sus hijas. Ya fuese debido a una u otra razón, es un hecho que a partir del 26 de junio de 1629 Catalina Juares se convertirá en la segunda esposa de Francisco Heylan ${ }^{61}$, de quienes no se ha podido encontrar por el momento si tuvieron o no descendencia.

Una nueva incorporación se producirá en 1626 en el hogar de los Heylan. Ese año llegará a casa de Francisco Heylan un joven de 21 años llamado Juan Mayor ${ }^{62}$ procedente de Bremen, Alemania, quien se hospedará en casa de Francisco a petición de sus padres $^{63}$. Se sabe que el joven Juan llegó a la Península en un barco que atracó en el puerto de Málaga ${ }^{64}$ y que venía acompañado por dos amigos de los que se separó nada más desembarcar. Juan Mayor vendrá formado de su tierra en el arte de la platería ${ }^{65} \mathrm{y}$ se convertirá en el futuro marido de Ana Heylan. Matrimonio que se celebró el 25 de mayo de 1630, cuando la joven Ana contaba solamente con quince años de edad y Juan con veinticinco.

En el mismo año en el que se celebrará el enlace de Francisco con Catalina Juares tendrá lugar el casamiento del hermano pequeño de Francisco, Bernardo Heylan quien por entonces contaba con 40 años de edad. El 26 de febrero de 1629 Bernardo contrajo matrimonio con María de las Nieves de Vargas en la Parroquia de Nuestra Señora de las Angustias de Granada. Para la conformación del expediente matrimonial, fechado el 10 de febrero de 1629, su hermano Francisco ejerció como testigo ${ }^{66}$, y junto con su hija Ana Heylan serían padrinos de velación ${ }^{67}$ en la boda.

Si en esta década de los años veinte se produjeron importantes cambios en la familia de los Heylan, en lo profesional a Francisco no le pudo ir mejor. Para este tiempo el cabeza de familia gozaba de un prestigio como grabador e impresor excepcional. Este es el momento donde Francisco deja de identificarse en los documentos oficiales como

60 Ibid.

61 Ibídem., fols. 1r.-3r.

62 Juan Mayor dice tener 25 años de edad en la confesión que realiza, él mismo, para conformar el expediente matrimonial, para su casamiento con Ana Heylan. Expediente Matrimonial de Anna Heylan con Juan Mayor... AHDGr. Serie Expedientes Matrimoniales, Sección Vicaría, Leg. 126/11, fol. 1v.

63 Hijo de Juan de Mayar y de María Midelstat, naturales de Bremen, Alemania. Ibídem., fol. 3r.

64 Ibídem., fol. $3 \mathrm{v}$.

65 Ibidem., fol. $2 \mathrm{r}$.

66 Expediente Matrimonial de Bernardo Heylan con... AHDGr. Serie Expedientes Matrimoniales, Sección Vicaría, Leg. 1679, p.6 [1629], Fol. 3r.-3v. Cfr. MORENO GARRIDO, Op. cit., 1976, Doc. IV, p. 162.

67 Registro Matrimonial de Bernardo Heylan con doña María de las Nieves en la Parroquia de Nuestra Señora de las Angustias. Granada a 26 de febrero de 1629. AHDGr. Libro de Matrimonios y velaciones de la parroquia de Nuestra Señora de las Angustias, Micro. 1297449/3. Año 1629, fol. 156r. 
abridor y cortador de láminas finas -a pesar de que siga ejerciendo esta profesión hasta el final de sus días-, para empezar a firmar en ellos como impresor ${ }^{68}$. En las labores de imprenta empezó a ocuparse ya por el 1617 con el trabajo de la Relación breve de la Reliquias... que realizó para el Sacro Monte. Actividad, que como ya se ha dicho no ejerció en solitario. Desde el principio compartió esta labor con su hermano Bernardo Heylan y tras 1624 se sumaría el impresor Andrés López.

El reconocimiento que tuvo Francisco Heylan en lo profesional es parangonable con el que obtuvo en lo social. Son numerosas las menciones hacia su persona que lo distinguen como un hombre de elevada consideración. Se insiste en su procedencia noble, como hijodalgo con escudo de armas propio, al que se uniría la posición social de su primera esposa Doña Ana de Godoy, la cual procedía de la alta nobleza de Baza ${ }^{69}$. Esto junto al éxito profesional permitirá disfrutar a la familia de una vida bastante acomoda$\mathrm{da}^{70}$. Esta condición permitirá que la familia funde un convento de Beguinas en su tierra natal, Amberes ${ }^{71}$. Si se tiene en cuenta lo declarado en la documentación encontrada se podría concluir que dicho convento pudo ser dotado en torno a la primera mitad de los años veinte entre 1623 y 1624, cuando Francisco gozaba de una estabilidad familiar y laboral. La creación de este patronato se podría considerar como un medio para adquirir ciertos beneficios de cara a las rentas de la familia, al que se sumarían los beneficios impositivos por ser considerados hijosdalgo.

68 Así lo reconocen algunos de los testigos que declaran en el expediente matrimonial del casamiento de Francisco Heylan con Catalina Juares. Entre ellos Ana de Valenzuela mujer de Andrés López impresor que estuvo trabajando en el obrador de Francisco durante al menos cinco años, entre 1624 y 1629 fecha de la declaración. Período en el que la imprenta de Francisco empezará a experimentar un progresivo aumento de su producción tipográfica. Expediente Matrimonial de Francisco Heylan con Catalina ..., AHDGr. Serie Expedientes Matrimoniales, Sección Vicaría, Leg. 121/180, fols. 2v.-3r.

69 Expediente de limpieza de sangre de Silvestre Heylan... AASM. Leg. 129, Fol. 7r.

70 Así lo expresó la Madre Antonia de Jesús cuando relatava la entrada en el beaterio de María de Santa Clara, la hija mediana de Francisco Heylan y doña Ana de Godoy, eran hijas «de buenos padres». BOHÓRQUEZ, Op. cit., 1995, p. 42.

71 El Beguinages también conocido en alemán como Begijnhoven, surgió en la edad Media como un conjunto de comunidades femeninas, donde mujeres más o menos independientes querían vivir una vida de devoción sin demasiadas ataduras. Funcionaban como pequeñas ciudades organizadas. Pero frente al resto de congregaciones religiosas que se regían por una serie de votos perpetuos, las beguinas disponían de un único voto temporal, el de la castidad. No tenían voto de obediencia de manera que podían dejar el beaterio sin romper con ello ningún compromiso formal, aunque una vez desligadas de la comunidad ya no podrían volver a ella. Ni tampoco contaban con el voto de pobreza. De manera que podían mantener sus propios bienes e incluso trabajar para su propio beneficio. Sin embargo, se esperaba de ellas que tuvieran una vida sobria sin exhibición de su riqueza. El primer Beguinage de Amberes se fundó en torno a 1240 y se situaba al sur de las murallas de la ciudad, lo que las hacía vulnerables ante cualquier asalto. De hecho cuando las tropas francesas se dirigieron hacia Amberes y el rey Francisco I dirigido por Maarten van Rossum no pudo capturar la ciudad en 1542, comenzaron a saquear la zona exterior de las murallas destruyendo en primer lugar el Beguinage. Esto dio lugar a que a partir de entonces las nuevas comunidades se construyesen dentro de la línea de muralla de la ciudad de Amberes. NEEL, Carol: «The Origins of the Beguines». Signs, 14 (Winter 1989), p. 334. Para tener más noticias sobre este tipo de beaterios véanse KOORN, Florence: «Women without Vows: The Case of the Beguines and the Sisters of the Common Life in the Northern Netherlands.» Women and Men in Spiritual Culture, XIV-XVII Centuries: A Meeting of South and North. Ed. Elisja Schulte van Kessel. The Hague: Netherlands Government Publishing Office, 1986; MCDONNELL, Ernest W.: The Beguines and Beghards in Medieval Culture. New Brunswick, NJ: Rutgers University Press, 1969; PETROFF, Elizabeth A.: Medieval Women's Visionary Literature. New York: Oxford University Press, 1986. 
«[...] Bernardo Heilan Abuelo del pretendiente y Francisco Heilan su visaguelo fueron fundadores de un convento de monjas media legua de la ciudad de Amberes, a quien llaman vulgarmente las las (sic) Veginas que lo dotaron magnificamente con muchas plaças para que entrasen por obra pia y presentacion todas las personas desçendientes de esta familia, que grauaron, y pusieron en el dicho convento sus Armas, y esto lo saue por auerlo oido decir a la Señora doña Ysauel Giron, señora que fue de Cardela y murio en el convento del Angel de esta ciudad y a su capellan don Pedro Clavijo los quales dos personas dijeron al testigo que auian estado en dicho convento y visto todo lo referido por que el dicho don Pedro Clauijo antes de pasar de esta ciudad a la de Amberes en asistencia de la dicha señora doña Ysauel Giron conocia mui bien en esta ciudad a la familia de las personas referidas en esta informacion del apellido Heilan $\gg^{72}$.

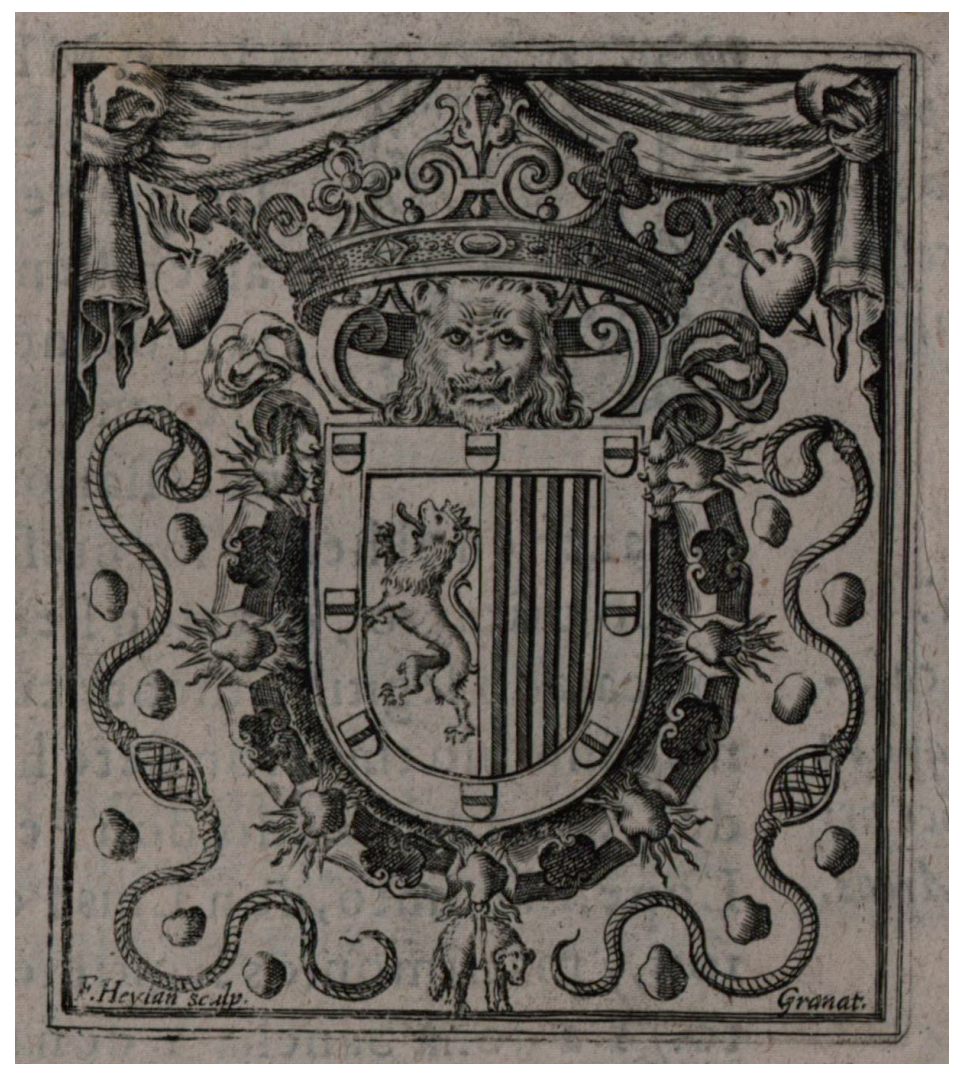

Fig. 3. Francisco Heylan. Escudo de armas. Duque de Arcos. Talla dulce, 1633, plancha retallada. [F.Heylan sculp. / Granat.]. Huella: 83 x $71 \mathrm{~mm}$. En: ARCOS, Duque de: [Por el Dvque de Arcos don Rodrigo Ponce de Leon. En el pleyto. Con don Diego fernandez de Cordoua Ponce de Leon, vezino de la Ciudad de Cordoua. Sobre: La demanda del dicho estado de Arcos, con sus acrecentamientos, que el dicho D. Diego le tiene puesta al dicho Duque]. Granada: por Vicente Aluarez [En la calle del Pan], 1633. C ARAH. 9/1499(31).

72 Expediente de limpieza de sangre de Silvestre Heylan... AASM. Leg. 129, Fol. 7r.-7v. 
Frente al éxito y prosperidad experimentada por Francisco Heylan durante los años veinte, la década de los años treinta estuvo marcada por un progresivo declive en lo profesional. Sin un hijo varón como heredero que continuara su labor en la imprenta, Francisco se vio abocado al arrendamiento de su parte a Juan Serrano de Vargas probablemente en torno a $1633^{73}$, cuando sólo contaba con 48 años de edad. Hecho en el que pudo influir una situación de enfermedad de Francisco, tal y como se ha venido indicando. Tampoco queda claro el grado de implicación que pudo tener Bernardo Heylan en la compañía de su hermano Francisco y Martín Fernández Zambrano. Si de verdad era un trabajo tan productivo ¿por qué no se quedó Bernardo con la parte de Francisco haciéndose cargo de la imprenta?

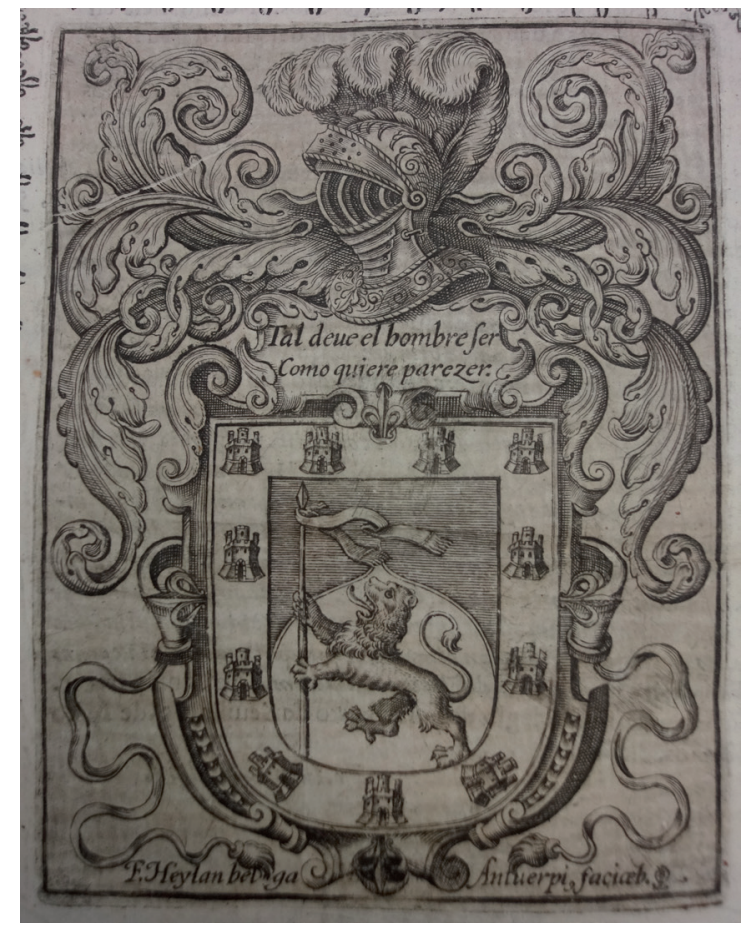

Fig. 4. Francisco Heylan. Escudo de armas: Don Fernando Pérez del Pulgar y Sandoval, Señor de la villa del Salar. Talla dulce, 1635. [F. Heylan belga / Antuerpi, faciæb (y el símbolo de la Granada)]. Huella 123 x 96 mm. En: ANGULO Y PULGAR, Martín de: Epistolas satisfatorias. Vna a las obieciones que opuso a los Poemas de D. Luys de Gongora el Licenciado Francisco de Cascales ... en sus cartas filologicas, otra a las proposiciones que contra los mismos poemas escriuio cierto Sugeto graue y docto. Granada: [en casa de] Blas Martinez, 1635. (C) BHR/Caja IMP-2-030 [Olim. C-40-174].

73 Los últimos impresos que aparecen firmados por Francisco Heylan están fechados en 1632. De ahí que exista la posibilidad de que para 1633 Francisco arrendara todos sus útiles de imprenta a Juan Serrano de Vargas, quien pleiteará contra la familia Heylan en 1640 a propósito del encarecimiento de la tasación realizada de dichos materiales los cuales consideraba que estaban arruinados por desgaste. 
Es muy discutible el motivo por el que se pudo producir el cese en 1633 de la actividad tipográfica de Francisco Heylan, pero sí se ha podido constatar que todos los útiles tipográficos de su taller fueron a parar a manos del impresor Juan Serrano de Vargas con quién el grabador había acordado una carta de arrendamiento con posibilidad de compra ${ }^{74}$. Sin embargo, esta operación no terminaría tan favorablemente para la familia Heylan como cabría esperar, ya que al tiempo las hijas de Francisco se verían envueltas en un pleito interminable a propósito de la demanda interpuesta por Serrano de Vargas ante la tasación excesiva del material que había adquirido el cual se encontraba, según su consideración, en un estado de evidente desgaste ${ }^{75}$.

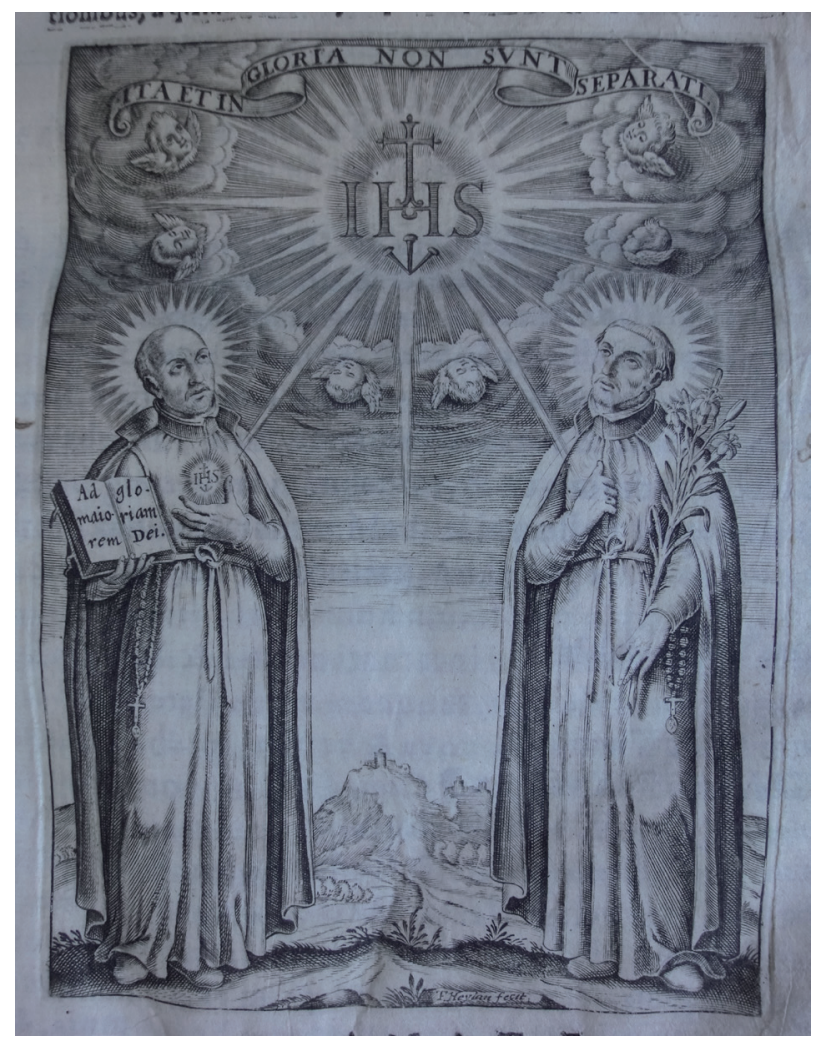

Fig. 5. Francisco Heylan. San Ignacio de Loyola y san Francisco Javier. Talla dulce, 1633. [F. Heylan fecit]. Huella 140 x 103 mm. En: GRANADO, Diego (S.I.): R.P. Iacobi Granado ... In Tertiam partem S. Thomae Aquinatis commentarii, in duos tomos distincti... Granatae...: typis Antonii Rene de Lazcano..., 1633. (C) BPJ. N-944.

74 Escritura de venta de la imprenta de Francisco Heylan a Juan Serrano de Vargas. Málaga, a 17 de julio de 1644. AHPM. Protocolo 1724, de Jerónimo de Hoz, fols. CCCCLXXIr.-CCCCLXXVIv. Cfr. JORDÉN, Op. cit., 1973, p. 42.

75 Gaspar Andres de Molina y Lorenzo Fonllana, poder otorgado por el impresor Juan Serrano de Vargas. Málaga, a 22 de diciembre de 1640. AHPM. Protocolo 1479, de Andrés Godinez de Zaragoza, fols. CCLXIr.CCLXIIr. Cfr. JORDÉN, Op. cit., 1973, p. 42. 
El cese de la imprenta en 1633 irá acompañado por un descenso en su producción calcográfica, cuyos grabados se encontrarán estampados de manera puntual en publicaciones de otros impresores. Para ese año Francisco Heylan no se debía encontrar en un estado de salud favorable, pues en el periodo que va de 1632 a 1635, año en el que estimamos que Francisco Heylan pudo fallecer, el grabador tan sólo realizó la estampación de dos escudos de armas que ya habían sido abiertos con anterioridad, como fueron el Escudo de armas del Duque de $\operatorname{Arcos}^{76}$ (fig. 3), y el Escudo de Armas de Pérez del Pulgar ${ }^{77}$ (fig. 4). En1633 abrió la pequeña estampa con las figuras de San Ignacio de Loyola y san Francisco de Borja ${ }^{78}$ (fig. 5), para la portada de la tercera parte de los comentarios de la Summa Theologica de Santo Tomás, que fueron publicados por Diego Granado. Y realizó el Frontispicio arquitectónico ${ }^{79}$ (fig. 6) para la obra de Torreblanca, que muy probablemente fue tallada hacia finales de 1634 y en la que no se debe descartar la posible colaboración de su hija Ana Heylan. Quién para entonces, ya se encontraba plenamente formada en el manejo del grabado a buril.

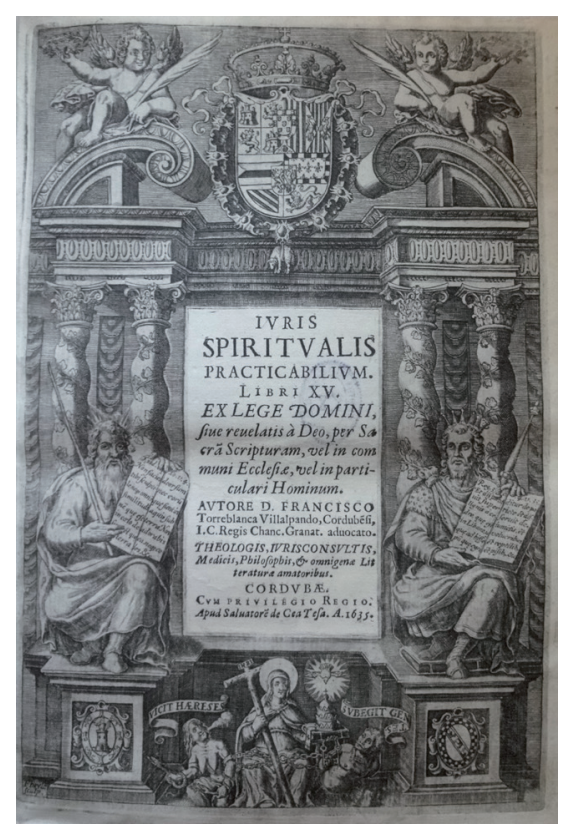

Fig. 6. Francisco Heylan. Frontispicio arquitectónico. Moisés, el Rey Salomón y la alegoría de la Religión encadenando a la herejía y a los gentiles. Talla dulce, 1635. [F heyla / sculp].

Huella 272 x $181 \mathrm{~mm}$; huella del hueco central 111 x $65 \mathrm{~mm}$. En: TORREBLANCA VILLALPANDO, Francisco: Iuris Spiritualis Practicabilivm..., Cordoba: Salvador Cea Tesa, 1635. (c) BASM. E-15/T-2/N-8.

\footnotetext{
76 PÉREZ GALDEANO, Op. cit., 2014, Vol. IV/Parte 3 y 4, Cat.7-141, pp. 627.

77 Ibidem., Vol. IV/Parte 3 y 4, Cat.7-145, pp. 639.

78 Ibídem., Vol. IV/Parte 3 y 4, Cat.7-142, pp. 631.

79 Ibidem., Vol. IV/Parte 3 y 4, Cat.7-144, pp. 635.
} 
Volviendo a lo que respecta al año del posible fallecimiento de Francisco Heylan, tradicionalmente este se había venido estableciendo en torno a $1650^{80}$, ante la falta de fuentes documentales que concluyeran una fecha más concreta. Este dato que se ofrecía quedaba justificado por la serie de publicaciones en las que se hallaban algunas de las estampas de Francisco, sin pensar que éstas pudieron ser incorporadas tras su muerte. Esas publicaciones, la mayoría impresos de carácter legal de finales de los cuarenta y segunda mitad del siglo XVII, iban acompañadas de estas estampas, que ahora se sabe procedían de matrices abiertas con anterioridad a 1635. Sus estampaciones pudieron correr a cargo de Bernardo o Ana Heylan, aunque tampoco se debería descartar la hipótesis de que algunas planchas hubieran sido adquiridas por otros impresores en almoneda tras el fallecimiento de Francisco. Dos impresores quedan destacados por el empleo de dichas estampas en sus publicaciones, Francisco Sánchez y Baltasar de Bolíbar, impresores de quiénes se puede constatar el uso reiterado de algunos de los grabados de Francisco Heylan, como fue el caso del Escudo de Don Luis Fernández de Córdoba y Ayala, Marqués de Valenzuela ${ }^{81}$; el Escudo de la Orden de Mínimos ${ }^{82}$; Escudo de Don Fernando Pérez del Pulgar y Sandoval, Señor de la villa del Salar ${ }^{83}$; Escudo de la ciudad de Granada con los Reyes Católicos ${ }^{84}$; Escudo de armas. Duque de Arcos ${ }^{85}$; Inmaculada Concepción ${ }^{86}$.

80 Moreno Garrido adoptó el año de fallecimiento de Francisco Heylan de 1650 ofrecido por algunas autoridades, ante la falta de documentos que indicasen con exactitud su defunción del grabador. WURZBACH, Alfred von: Niederlandisches Künstlerlexikon. Viena: Lipsia, 1906-1911, v. 1, p.689. Noticia que, a su vez, fue recogida posteriormente en los grandes diccionarios de Benezit y Hollstein. BENEZIT, Emmanuel: Dictionnaire critique et documentaire des peintres, sculpteurs, dessinateurs et graveurs de tous les temps et de tous les pays. Paris: Gründ, 1999, v. IV, p. 695; HOLLSTEIN, F.W.H.: Dutch and Flemish etchings, engravings and woodcuts ca. 1450-1700. Amsterdam: Menno Hertzberger, 1953-1956, t. IX, p. 32. Cfr. MORENO GARRIDO, Op. cit., 1976, nota 26, p. 62.

81 VANDER HAMMEN Y LEÓN, Lorenzo: Modo de llorar los pecados..., Granada: Baltasar de Bolibar y Francisco Sánchez, 1649. BArzGr. B-907.

82 MÍNIMOS, Orden de los: Illiberitana Minorum Provincia pro Comitiis Provincialibus congregata ... in hoc granatensi coenobio Diuae Mariae a Victoria sacro a luce 24 septembris usque ad primam octobris, anno 1659. Granatae: [ex Typographia Regia] apud Balthasarem de Bolibar, 1659. BHR/A-031-258 (7).

83 HERRERA Y ROZAS, Sebastián de: Oraciones panegyricas, predicadas en la Iglesia Mayor de la ciudad de Loxa...,. Granada: Baltasar de Bolibar [en la calle Abenamar], 1664. BGUS. A 112/115(10).

84 [2 ${ }^{\mathrm{a}}$ tirada] PARACUELLOS, Luis de: Trivnfales celebraciones qve en aparatos magestvosos consagro religiosa la civdad de Granada, a honor de la Pureza Virginal de Maria Santissima en sus desagrauios, a quien deuota las dedica esta Ciudad en todo Ilustre, en todo Grande. Granada: Francisco García de Velasco, 1640. Cotejados los fondos de: BNE. R/153 y BH. FLL 3067; [3 $3^{\mathrm{a}}$ tirada] GRANADA, Andrés de (O.F.M. Cap.), Sermon en las honras funerales y exequias magestuosas que al inclito Rey D. Fernando el Catolico le celebro y hizo en veynte y quatro de enero deste presente año de mil y seyscientos y cincuenta el ilustrissimo Cabildo Eclesiastico de la muy leal ciudad de Granada ... / Predicolo el Padre Fr. Andres de Granada, religioso de la Orden de N. P. S. Francisco de Capuchinos ... Granada: Baltasar de Bolibar y Francisco Sanchez, 1650. Cotejado los fondos de: BHR A-31-205(13) y BHR A-31-208(16); [4 tirada] MÍNIMOS, Orden de los: Illiberitana Minorum Provincia pro Comitiis Provincialibus congregata ... in hoc granatensi coenobio Diuae Mariae a Victoria sacro a luce 24 septembris usque ad primam octobris, anno 1659. Granatae: [ex Typographia Regia] apud Balthasarem de Bolibar, 1659. BHR/A-031-258 (7).

85 [4 ${ }^{\mathrm{a}}$ tirada; $2^{\mathrm{a}}$ retalla; $3^{\text {er }}$ estado] GUZMÁN SARABIA, Sancho de: Arco Trivnfal de Himeneo, en las Heroycas bodas de el Excelentissimo Señor Don Francisco Ponze de Leon..., impreso en Granada por Baltasar de Bolibar, [En la calle de Abenamar] en 1654. BNE. R/11453(6); BNE. VE/154(35).

86 [ $5^{\mathrm{a}}$ tirada?, $2^{\mathrm{a}}$ retalla, $3^{\mathrm{a}}$ estado] GONZALEZ DE SEPULVEDA, Matías. [Informacion en favor del rey nvestro señor, y su Real Patrimonio, y de el comun y Iurados de la Ciudad de Huete, y de las demas Ciudades, 
Gracias a una serie de nuevos documentos encontrados ha sido posible proporcionar una cronología más cierta que la facilitada con anterioridad, sobre el año en el que pudo acontecer el fallecimiento de Francisco Heylan, que ahora se estima en 1635. Se ha logrado llegar a esta averiguación entre otros, a través de la lectura de los poderes notariales fechados entre el 20 de septiembre de 1640 y el 17 de julio 1644 en los cuales se menciona que para dicho año Francisco Heylan ya se encontraba difunto ${ }^{87}$. Este ha sido el primer indicio concluyente para determinar que Francisco no había fallecido en 1650. El primer documento que citamos es un auto de nombramiento de Juan de Anaya como procurador de Elena de la $\mathrm{Cruz}^{88}$, hija menor de Francisco Heylan que para entonces profesaba como religiosa beata de la orden de san Agustín en el beaterio de santo Tomás de Villanueva (hoy convento de las Tomasas) en el barrio del Albaycín. Este documento otorgaba poderes al letrado para representar a la joven en dos pleitos que la familia mantenía contra dos impresores. El primero contra Martín Fernández Zambrano, «con quien el dicho Francisco de Hilan puso y asento compañia en el arte de la enprenta (sic) y sobre ello pedirle quenta de las ganan/ cias y suerte principal del tiempo que la tubieron» ${ }^{89}$. Y el segundo, para defender a la joven en Málaga contra el impresor Juan Serrano de Vargas, quien exigía una indemnización a cuenta de la elevada tasación que a su parecer se hizo del material que Francisco Heylan le arrendó, el cual se encontraba deteriorado ${ }^{90}$. El segundo documento referido es la escritura de venta de los útiles de imprenta de Francisco Heylan ${ }^{91}$ fechado el 17 de julio de 1644, donde se vuelve a insistir que para entonces Francisco Heylan ya se encontraba difunto «Maria de Santa Clara y de Elena de la Cruz herma/ nas veatas, relixiosas de Señor San Agustin en el convento descalsos de la dicha ciudad de Granada. Hijas lexitimas y natura/les de Francisco Yllan difunto ynpressor de libros vezino que fue de la dicha ciudad y sus herederas ${ }^{92}$. Pudiéndose así descartar

villas y lugares de estos Reynos. Hecha por el Doctor Mathias Gonçalez de Spulueda Fiscal de su Magestad en la Real Chancilleria. Contra el Doctor Ivan Nvñez Carrillo y consortes vezinos de la dicha Ciudad de Huete, sobre la hidalguia de sangre y propriedad que pretenden]. [s.1., Granada: s.n. Francisco Sánchez y Baltasar de Bolibar, s.a.]. BNE. PORCONES/849(18).

87 Poder otorgado por doña María Heylan. Granada, 20 de septiembre de 1640. AHDGr. Protocolos, Caja 44, de Hipólito Barrientos, fol. 927r; Poder otorgado a Juan de Anaya. Granada, 11 de octubre de 1640. AHPrGr. Protocolo 672, de Andrés Álbarez, fols. 782r.-782v; Poder otorgado por doña María de Yllan a Juan de Anaya. Granada, 11 de octubre de 1640. AHPrGr. Protocolo 672, de Andrés Álbarez, fols. 782v.-783r; Juan de Anaya acepta el nombramiento de procurador de María Heylan. Granada, 11 de octubre de 1640. AHPrGr. Protocolo 672, de Andrés Álbarez, fols. 783r.-783v; Escritura de venta de los útiles de imprenta de Francisco Heylan a Juan Serrano de Vargas. Málaga, a 17 de julio de 1644. AHPM. Protocolo 1724, de Jerónimo de Hoz, fols. CCCCLXXIr.-CCCCLXXVIv. Cfr. JORDÉN, Op. cit., 1973, p. 42.

88 Auto de nombramiento de Juan de Anaya como procurador de Elena de la Cruz [Heylan]. Granada, 7 de octubre de 1640. AHPrGr. Protocolo 672, de Andrés Álbaros[rez], fol. 850r.-851v.

89 Ibídem. Fol. 850r.

90 Ibid.

91 Escritura de venta de los útiles de imprenta de Francisco Heylan a Juan Serrano de Vargas. Málaga, a 17 de julio de 1644. AHPM. Protocolo 1724, de Jerónimo de Hoz, fols. CCCCLXXIr.-CCCCLXXVIv. Cfr. JORDÉN, Op. cit., 1973, p. 42.

92 Ibídem., fol. CCCCLXXIr. [471r.] 
de manera taxativa el año de defunción de Francisco Heylan que tradicionalmente se había venido señalando en $1650^{93}$.

A pesar de las trascendentales noticias aportadas por los documentos de archivo, aún éstas mantenían muy lejana la estimación del año de fallecimiento del grabador con respecto a la hipótesis que aquí se plantea. De manera que era necesario aportar nuevas fuentes capaces de ofrecer datos más concluyentes al respecto. En este sentido ha sido determinante el relato de las Fundaciones ${ }^{94}$ de la Madre Antonia de Jesús, donde se narra la convulsa entrada de las dos hijas pequeñas de Francisco (María y Elena) en el beaterio vinculado a la orden de San Agustín instalado en el barrio del Albaycín. Este relato de la Madre Antonia de Jesús ha permitido proponer una cronología más aproximada sobre dicho asunto.

Se ha sabido que las dos hijas pequeñas de Francisco Heylan, María Heylan Estébanez y Elena Heylan Estébanez, se encontraban huérfanas de padre y madre y viviendo bajo la tutela de Ana Heylan y Juan Mayor, al menos desde abril de $1636^{95}$. En este año la Madre Antonia recibirá en el beaterio a la primera de las hermanas Heylan, Elena que era la más pequeña, cuando la joven contaba con 13 o 14 años de edad ${ }^{96}$.

La incorporación de María Heylan al beaterio agustino se hará realidad hacia 1641 después de un primer intento fallido en $1636^{97}$, y lo hará bajo el nombre de María de Santa Clara. Este periodo concuerda con el testimonio ofrecido por la Madre Antonia de Jesús ${ }^{98}$ y con la fecha contenida en el protocolo de 1640 donde María firma todavía como «joven doncella» ${ }^{99}$ de 22 años de edad ${ }^{100}$. Poco después, en el protocolo de 1644 María ya aparecerá nombrada religiosa beata de la orden agustina, tiempo para

93 Wurzbach, Benezit, Hollstein, entre otros. Véase la nota 82.

94 BOHÓRQUEZ, Op. cit., 1995, pp. 30-31; 42-45; 146-147.

95 El 2 de abril de 1636 la joven Madre Antonia de Jesús se instalará en una pequeña casita vinculada al convento de la orden de los Agustinos, donde recibirá en el paso de unos meses a la primera de las hermanas Heylan, Elena. BOHÓRQUEZ, Op. cit., 1995, p. 22.

96 Fecha estimada a partir del protocolo fechado en 1640 Auto de nombramiento de Juan de Anaya como procurador de Elena de la Cruz [Heylan]. Granada, 7 de octubre de 1640. AHPrGr. Protocolo 672, de Andrés Álbaros[rez], fol. 850r.-851v. Aquí se indicaba que Elena contaba por entonces con 17 años de edad, y para el que necesitaba la firma de la Madre Antonia de Jesús, superiora del beaterio y por tanto su tutora jurídica. A partir de ahí, podemos establecer que para el año 1636, Elena contaría aproximadamente con 13 o 14 años, dependiendo de su fecha de nacimiento, — cuestión que todavía no se ha podido concretar-. De ahí que la superiora indique cuando recibe a la joven en el beaterio «A mí me parecía que era muy niña, y ella parece que entendió mi pensamiento, y me dijo que aunque era pequeña de cuerpo, que tenía más años de los que parecía». BOHÓRQUEZ, Op. cit., 1995, p. 30.

97 Ibid.

98 «Después de haberse retirado de mí, quedé yo con tan grandes deseos de que Dios me diese aquella alma, que noches ni días cesaba en pedírselo a Su Majestad; y como su hermana no quería que yo entrase en su casa, le rondaba la puerta, como si fuese su galán, mirando a las ventanas, y algunas veces rodeaba muchos pasos para poder pasar por su puerta por si la podía hablar. Anduve cuatro años desta suerte, hasta que quiso Dios que su hermana se desenojó y me dió (sic) entrada, y con esto la veía y amonestaba, y ella era de tan dócil natural que, luego que la hablaba algo de desengaño, se enternecía y lloraba.» Ibídem., pp. 42-43.

99 Poder otorgado por doña María Heylan. Granada, 20 de septiembre de 1640. AHDGr. Protocolos, Caja 44, de Hipólito Barrientos, fol. 927r.

100 Poder otorgado por doña Maria de Yllan a Juan de Anaya. Granada, 11 de octubre de 1640. AHPrGr. Protocolo 672, de Andrés Álbarez, fols. 782v.-783r. 
el cual la joven contaría con 26 años de edad ${ }^{101}$ y ejercería como madre superiora del beaterio, el cual gobernará hasta su muerte. De manera que los datos ofrecidos en las Fundaciones son totalmente fiables y un parámetro importante para determinar la muerte de Francisco Heylan para el año 1635.

\section{Conclusión}

A modo de conclusión diremos que en relación a los datos biográficos de Francisco Heylan, se ha de realizar una modificación considerable en las biografías hasta ahora conocidas. Se ha revisado y se han incorporado nuevos miembros que conforman el árbol genealógico de este grabador e impresor (fig. 7). Y se han dado a conocer un número considerable de nuevas fuentes documentales que permiten elaborar con mayor exactitud y profundidad los datos referidos a su biografía. Ha quedado como dato destacado la resituación del año de la muerte del principal miembro de la saga de los Heylan, Francisco. Además se ha puesto de manifiesto el estatus social detentado por esta familia en su origen, como en su establecimiento en Granada.

Se espera de futuros estudios nuevas aportaciones concernientes a las biográficas del resto de miembros de su familia, como también se pretende abordar otros estudios relativos a su estilo, mecenazgo y clientela, como los referidos a su producción en el arte de la imprenta.

Abreviaturas de los Centros de documentación

$\begin{array}{ll}\text { AASM } & \text { Archivo Abadía del Sacro Monte, Granada } \\ \text { AASA } & \text { rchivo Arzobispal de Sevilla } \\ \text { ACS } & \text { Archivo Capitular de Sevilla } \\ \text { AGAS } & \text { Archivo General Arzobispado de Sevilla } \\ \text { AHDGr } & \text { Archivo Histórico Diocesano, Granada } \\ \text { AHN } & \text { Archivo Histórico Nacional de España } \\ \text { AHPM } & \text { Archivo Histórico Provincial de Málaga } \\ \text { AHPrGr } & \text { Archivo Histórico de Protocolos, Granada } \\ \text { AIM } & \text { Archivo Iglesia de San Miguel, Granada } \\ \text { AIJRR } & \text { Archivo de San Juan de los Reyes, Granada } \\ \text { ARAH } & \text { Archivo de la Real Academia de la Historia, Madrid } \\ \text { BASM } & \text { Biblioteca Abadía del Sacro Monte, Granada } \\ \text { BArzGr } & \text { Biblioteca Arzobispal de Granada } \\ \text { BGUS } & \text { Biblioteca General Universidad de Sevilla } \\ \text { BH } & \text { Biblioteca Histórica (Marqués de Valdecillas), Madrid } \\ \text { BHR } & \text { Biblioteca Hospital Real, Granada } \\ \text { BNE } & \text { Biblioteca Nacional de España }\end{array}$

101 Escritura de venta de los útiles de imprenta de Francisco Heylan a Juan Serrano de Vargas. Málaga, a 17 de julio de 1644. AHPM. Protocolo 1724, de Jerónimo de Hoz, fols. CCCCLXXIr.-CCCCLXXVIv. Cfr. JORDÉN, Op. cit., 1973, p. 42. 


$\begin{array}{ll}\text { BPJ } & \text { Biblioteca Provincial de Jaén } \\ \text { BPM } & \text { Biblioteca Provincial de Málaga } \\ \text { BSMSJ } & \text { Biblioteca Seminario Mayor o Conciliar de San Julián, Cuenca } \\ \text { BV } & \text { Biblioteca Valenciana } \\ \text { MASM } & \text { Museo Abadía del Sacro Monte, Granada }\end{array}$

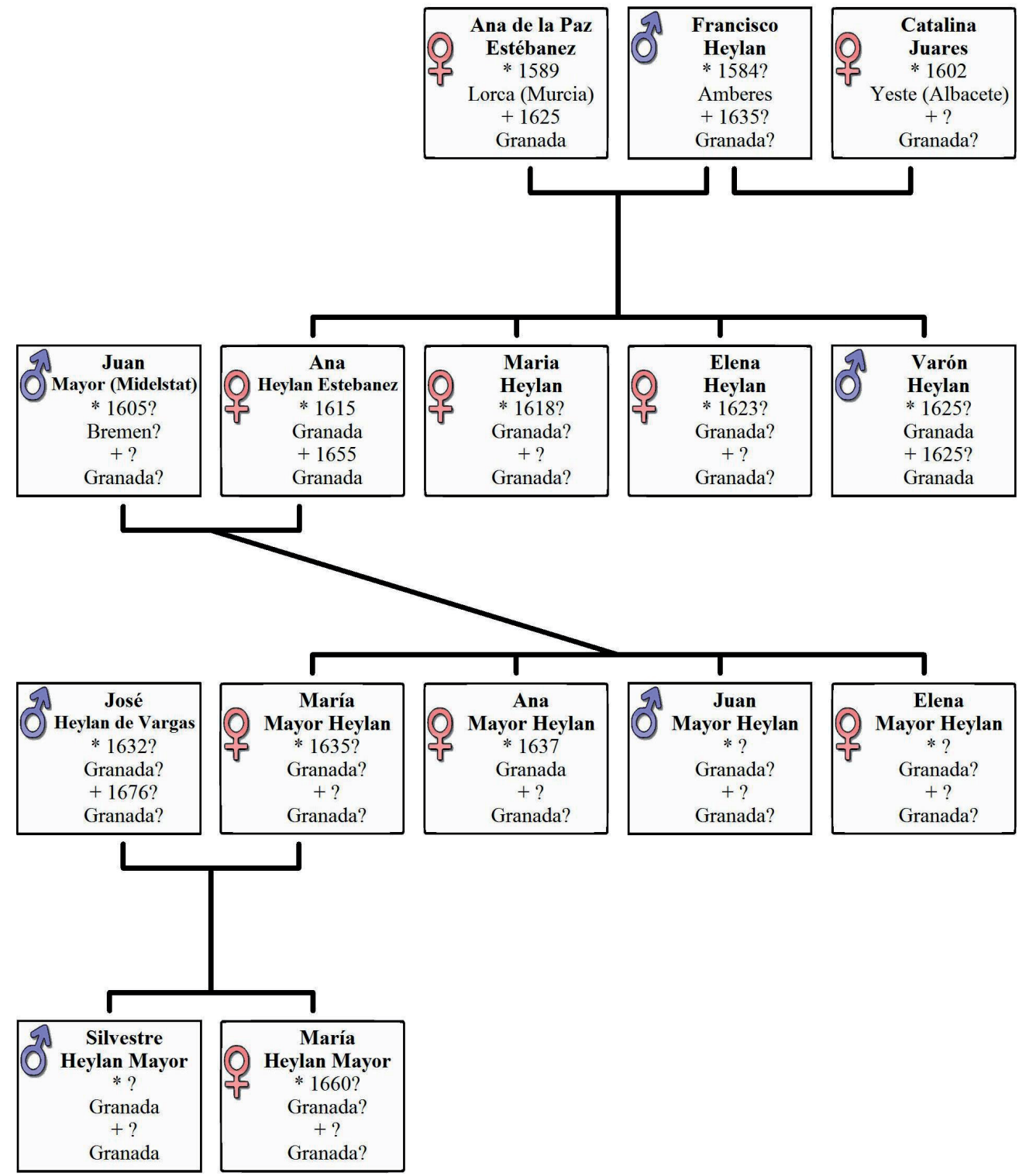

Fig. 7. Árbol genealógico de Francisco Heylan. 